\title{
Mechanisms Underlying Food-Drug Interactions: Inhibition of Intestinal Metabolism and Transport
}

\author{
Christina S. Won ${ }^{\mathrm{a}}$, Nicholas H. Oberlies ${ }^{\mathrm{b}}$, and Mary F. Paine ${ }^{\mathrm{a},{ }^{*}}$ \\ aDivision of Pharmacotherapy and Experimental Therapeutics, Eshelman School of Pharmacy, \\ University of North Carolina at Chapel Hill, Chapel Hill, NC 27599-7569 USA \\ bDepartment of Chemistry and Biochemistry, University of North Carolina at Greensboro, \\ Greensboro, NC 27402-6170 USA
}

\section{Abstract}

Food-drug interaction studies are critical to evaluate appropriate dosing, timing, and formulation of new drug candidates. These interactions often reflect prandial-associated changes in the extent and/or rate of systemic drug exposure. Physiologic and physicochemical mechanisms underlying food effects on drug disposition are well-characterized. However, biochemical mechanisms involving drug metabolizing enzymes and transport proteins remain underexplored. Several plantderived beverages have been shown to modulate enzymes and transporters in the intestine, leading to altered pharmacokinetic (PK) and potentially negative pharmacodynamic (PD) outcomes. Commonly consumed fruit juices, teas, and alcoholic drinks contain phytochemicals that inhibit intestinal cytochrome P450 and phase II conjugation enzymes, as well as uptake and efflux transport proteins. Whereas myriad phytochemicals have been shown to inhibit these processes in vitro, translation to the clinic has been deemed insignificant or undetermined. An overlooked prerequisite for elucidating food effects on drug PK is thorough knowledge of causative bioactive ingredients. Substantial variability in bioactive ingredient composition and activity of a given dietary substance poses a challenge in conducting robust food-drug interaction studies. This confounding factor can be addressed by identifying and characterizing specific components, which could be used as marker compounds to improve clinical trial design and quantitatively predict food effects. Interpretation and integration of data from in vitro, in vivo, and in silico studies require collaborative expertise from multiple disciplines, from botany to clinical pharmacology (i.e., plant to patient). Development of more systematic methods and guidelines is needed to address the general lack of information on examining drug-dietary substance interactions prospectively.

\section{Keywords}

food-drug interaction; intestine; metabolism; transport; inhibition; grapefruit

\footnotetext{
() 2012 Elsevier Inc. All rights reserved.

"Corresponding author: 2320 Kerr Hall; CB \#7569, UNC Eshelman School of Pharmacy, Chapel Hill, NC 27599-7569, USA, Tel.: 919-966-9984, Fax: 919-962-0644, mpaine@unc.edu (M. F. Paine).

Conflict of interest statement

The authors declare that there are no conflicts of interest.

Publisher's Disclaimer: This is a PDF file of an unedited manuscript that has been accepted for publication. As a service to our customers we are providing this early version of the manuscript. The manuscript will undergo copyediting, typesetting, and review of the resulting proof before it is published in its final citable form. Please note that during the production process errors may be discovered which could affect the content, and all legal disclaimers that apply to the journal pertain.
} 


\section{Introduction}

The impact of food on successful delivery of promising new drug candidates via the oral route poses a major challenge during drug development. The influence of dietary substances on drug disposition depends on numerous variables, ranging from physicochemical properties of the drug to postprandial changes in the gastrointestinal (GI) tract (Charman et al., 1997; Custodio et al., 2008). Components of the diet that modulate intestinal cytochrome P450 and phase II conjugation enzymes, as well as uptake and efflux transport proteins, constitute increasingly recognized contributors to food effects on drug disposition (Rodríguez-Fragoso et al., 2011). Many dietary substances or food ingredients derived from botanical sources have been shown to inhibit these processes in vitro, but translation to the clinic has been inconclusive or considered irrelevant (Farkas \& Greenblatt, 2008). Understanding the mechanisms by which these dietary substances alter drug PK and PD outcomes is critical to assess clinical significance and management.

Prediction of PK properties of new drug candidates entering clinical trials can be an arduous, sometimes elusive, task. The added complexity of food effects increases such difficulty. Robust guidelines on the evaluation of potential dietary substance-drug interactions are lacking (Abdel-Rahman et al., 2011). Clinical studies often are difficult to compare, inconclusive, and/or fail to meet strict criteria required to make definitive clinical and regulatory recommendations. Commercially available modeling and simulation software can be a valuable tool to evaluate and predict, quantitatively, potential dietary substance-drug interactions. A key contributing factor to predictive success is a thorough knowledge of the causative ingredient(s) contained in the dietary substance. Identification, characterization, and validation of specific bioactive components as marker compounds can guide appropriate clinical trial design. Such studies enable development and validation of PK-PD models describing the relationship between a given dietary substance and drug of interest. The current review provides an update on dietary substance-drug interaction research, addresses challenges and potential solutions regarding the conduct and interpretation of associated studies, and discusses in silico strategies for predicting food effects.

\section{Food-drug interactions}

\subsection{Definition}

A food-drug interaction is the consequence of a physical, chemical, or physiologic relationship between a drug and a product consumed as food or a nutrient present in a botanically-derived food or dietary supplement (Santos and Boullata, 2005; Genser, 2008). Such an interaction may manifest clinically as compromised health status due to altered PK and/or PD of the drug or dietary substance. Although dietary substances are regulated as food or dietary/herbal supplements, bioactive constituents in these substances can act like "perpetrator" drugs. That is, a dietary substance can increase systemic "victim" drug exposure (AUC), increasing the risk of adverse events and toxicity, or decrease systemic victim drug exposure, leading to therapeutic failure (Santos and Boullata, 2005). A lack of an interaction may be due to insufficient concentration(s) of causative ingredients at the enzyme or transporter active site, metabolism of causative ingredients to inactive products, or transport of causative ingredients out of target cells (e.g., enterocyte, hepatocyte). Underlying mechanisms by which food exerts such effects generally include physiologic, physicochemical, and/or biochemical processes (Fleisher et al., 1999). Elucidation of these processes in relevant organ systems is essential to resolve issues related to formulation, dosing schedule, and optimal pharmacotherapeutic strategies (Li et al., 2002; Lentz, 2008; Parrott et al., 2009). 


\subsection{Regulatory guidelines}

Potential clinically significant implications of food-drug interactions are recognized by worldwide regulatory agencies, each with specific guidelines. A guidance issued by the United States Food and Drug Administration (FDA) in 2002 provided recommendations on the design and conduct of food effect and fasted/fed state studies (http://www.fda.gov/cder/ guidance). High-calorie ( $800-1000$ calories) and high-fat ( $\sim 50 \%$ of total caloric content) test meals represent the 'worst-case scenario' and are expected to alter maximally GI physiology and subsequent systemic drug availability. Although examination of the effects of food consumption on the PK of drugs is standard practice, the issue has become greater than "take with or without food" since a variety of specific dietary substances has been shown to alter systemic drug availability. Evaluation of the underlying mechanism(s) can ultimately lead to firm conclusions required to make informed clinical and regulatory decisions or guidelines.

\section{Underlying mechanisms of food effect on drug exposure and response}

\subsection{Physiologic and physicochemical mechanisms}

Dietary substances can alter drug absorption, distribution, metabolism, and/or excretion (ADME) via physiologic and physicochemical mechanisms. Physiologic/mechanical mechanisms include delayed gastric emptying, stimulated/increased bile or splanchnic blood flow, and GI pH or flora changes. Alterations of such processes can lead to reduced absorption of some drugs (e.g., penicillins, angiotensin-converting enzyme inhibitors) (Singh, 1999). Physicochemical mechanisms include binding of the drug by the food. For example, enteral nutrition formulas are incompatible with the antiepileptic agent, phenytoin, which can bind to proteins and salts in enteral formulations, resulting in reduced phenytoin absorption and potentially inadequate seizure control (Lourenço, 2001). Some tetracyclines and fluoroquinolones can bind to divalent cation-containing products (e.g., calcium in dairy), resulting in reduced drug absorption (Jung et al., 1997; Polk, 1989) and potential therapeutic failure. High fat meals can increase drug absorption by improving solubility, such as with some antiretroviral protease inhibitors (e.g., saquinavir, atazanavir) (Plosker and Scott, 2003; Le Tiec, 2005). Other examples are discussed comprehensively in several sources (Wolinsky and Williams, 2002; McCabe et al., 2003; Boullata and Armenti, 2004; Meckling, 2007; Stargrove et al., 2008).

\subsection{Biochemical mechanisms}

Biochemical mechanisms include interference with co-factor formation or function, potentiation of drug PD, and modification of drug metabolizing enzyme/transporter function by the dietary substance (Chan, 2002). For example, vitamin K-rich foods interfere with cofactor function and should be consumed cautiously with the anticoagulant, warfarin, as they can disrupt vitamin $\mathrm{K}$ metabolism and increase risk of bleeding or clot formation (Holbrook et al., 2005). Isoniazid and monoamine oxidase inhibitors, used to treat tuberculosis and depression, respectively, inhibit the breakdown of endogenous and dietary amines; a tyramine-rich diet can potentiate a hypertensive crisis (Brown et al., 1989; Self et al., 1999). Foods consumed as beverages account for a very high proportion of dietary antioxidant intake (Pulido et al., 2003). Growing evidence supporting cardioprotective benefits promotes moderate consumption as part of a healthy lifestyle (Kaplan and Palmer, 2000; Guilford and Pezzuto, 2011). However, certain beverages contain substances that can influence drug disposition via modulation of drug metabolizing enzymes and transporters in the intestine.

Several studies have assessed the effect of wine, beer, fruit juices, tea, and specific constituents therein on CYP activity in vitro, but clinical studies are limited. These beverages have become highly recommended supplements to routinely prescribed and over- 
the-counter drugs and/or as monotherapy for prevention, treatment, and maintenance of common diseases. Some ingredients identified in fruit juices, teas, and alcoholic beverages have been shown to inhibit intestinal metabolism and active apical efflux/uptake processes in vitro and in vivo. Inhibition of metabolism and active efflux would be expected to increase, whereas inhibition of active uptake would be expected to decrease, systemic drug exposure. These biochemical mechanisms, specifically with respect to the intestine, are highlighted in the current review. Examples of other dietary substance-drug interactions are detailed in several sources (Wolinsky and Williams, 2002; McCabe et al., 2003; Boullata \& Armenti, 2004; Meckling, 2007; Stargrove et al., 2008).

\section{Inhibition of intestinal biochemical processes}

The clinical significance of the intestine as a barrier to drug absorption and as a site for drug-drug interactions (DDIs) is recognized widely (Tidball, 1971). Successful delivery of an oral drug to the target site encompasses a complex multifactorial process, requiring the identification of factors and mechanisms involved in optimal formulation design and the subsequent effects of interactions with the GI environment. A prime hindrance to drug absorption is the variety of drug metabolizing enzymes and transport proteins in the enterocyte that detoxify, bioactivate, and shuttle xenobiotics (Fig. 1). Environmental variables such as polypharmacy and diet add to the challenge of achieving therapeutic efficacy while avoiding toxicity or treatment failure (McCabe, 2004).

Purported health benefits of certain botanical products have led to their promotion as complements (or alternatives) to drug therapy (Espin et al., 2007). The popular consumption of fruit juices, teas, and alcoholic drinks is attributed not only to taste and nutritive value but also to increased awareness of the pharmacologic (e.g., antioxidant) effects of specific constituents (Gruenwald, 2009). However, in parallel, a growing number of in vitro and in vivo studies have demonstrated inhibitory, potentially detrimental, effects on enzymes and transporters involved in drug disposition, particularly those in the intestine, the primary portal for drugs and dietary substances (Huang et al, 2008). The proceeding sections describe the latest findings in beverage-drug interaction research.

\subsection{Phase I metabolism}

4.1.1. Cytochrome P450 3A-The cytochromes P450 (CYPs) are the predominant phase I enzymes involved in drug metabolism (Shen et al., 1997). Of the CYPs expressed in the intestine, the CYP3A subfamily is the most abundant and has been established to influence drug disposition in vivo (Lin and Lu, 2001; Paine et al., 2006). CYP3A is composed largely of CYP3A4 and CYP3A5 in adults. Enteric CYP3A4 is located primarily in the villous tips of the enterocytes lining the upper and middle third of the intestine (duodenum to distal jejunum) (Thummel and Wilkinson, 1998). CYP3A is responsible for the oxidative metabolism of more than half of pharmaceutical agents on the market (Gibbs and Hosea, 2003). The effects of several fruit juices on CYP3A expression and activity have been studied extensively in vitro and in human participants. Specific inhibitory ingredients in some fruit juices have been identified and characterized. In contrast, data on enteric CYP3A inhibition by teas and alcoholic beverages (e.g., wine, beer) are less abundant and the clinical significance remains to be determined.

Grapefruit juice (GFJ): Juice prepared from grapefruit (Citrus $\mathrm{x}$ paradisi Macfad.) is one of the most exhaustively studied dietary substances shown to inhibit enteric metabolism of numerous CYP3A substrates (Mertens-Talcott et al., 2006, Seden et al., 2010, Hanley et al., 2011). GFJ can enhance systemic drug exposure by inhibiting CYP3A-mediated presystemic (first-pass) metabolism in the intestine (Paine and Oberlies, 2007). Inhibition is localized primarily in the gut, as demonstrated by a lack of effect on the elimination half-life 
of orally administered substrates and on the PK of intravenously administered substrates (Kupferschmidt et al., 1995). The increase in systemic drug exposure can be sufficient to produce adverse events, such as muscle pain with some statins and severe hypotension with some calcium channel blockers (Saito et al., 2005). Compounds known as furanocoumarins (e.g., $6^{\prime}, 7^{\prime}$-dihydroxybergamottin, bergamottin), in aggregate, have been established as major mediators of the 'GFJ effect' in humans (Paine et al., 2006). Modes of intestinal CYP3A inhibition include reversible and mechanism-based (Schmiedlin-Ren et al., 1997; Paine et al., 2004; Paine et al., 2005), as well as degradation of the protein (Lown et al., 1997). Research on the impact of GFJ on drug disposition and response is reported and updated frequently. Table 1 summarizes the design and results of GFJ-drug clinical studies since the authors' previous review published in 2010 (Won et al., 2010).

Two unusual case reports on the effect of GFJ on CYP3A substrates administered intravenously were reported recently. One involved a 52 year-old Caucasian woman diagnosed with a locally advanced unresectable esophageal squamous cell carcinoma (Valenzuela et al., 2011). She began a docetaxel-containing $\left(40 \mathrm{mg} / \mathrm{m}^{2}\right.$ biweekly) chemotherapy regimen. After the first treatment cycle, the AUC of docetaxel was higher (65\%) compared to typical values. In parallel, hematologic toxicity, particularly a decrease in neutrophil count (by 71\%), was observed. After interviewing the patient and reviewing her medication history, the investigators concluded that GFJ was responsible for the decrease in docetaxel clearance. She reported drinking GFJ $(250 \mathrm{~mL})$ daily for more than three months. Two weeks after she was advised to cease drinking GFJ, docetaxel was administered. Relative to the first cycle, docetaxel AUC was reduced by $60 \%$, approximating the AUC target value. The other case involved an 83-year-old woman with a history of acute myocardial infarction and paroxysmal atrial fibrillation (Agosti et al., 2012). She presented to the emergency department with postprandial syncope and palpitations. Pharmacologic cardioversion was initiated by administering intravenous amiodarone (300 $\mathrm{mg}$ loading dose). Following administration, the electrocardiogram showed marked QT prolongation associated with ventricular arrhythmias, including an episode of torsade de pointes requiring immediate electrical cardioversion. When questioned about her eating habits, the patient reported regular GFJ consumption ( $\geq 1-1.5 \mathrm{~L} /$ day). After she was advised to cease drinking GFJ, the patient recovered and was discharged four days later. These two case reports are consistent with inhibition of hepatic CYP3A by GFJ when consumed regularly in copious atypical volumes (Lilja et al., 2000).

Seville orange juice: Juice prepared from the Seville (sour or bitter) orange (Citrus $\mathrm{x}$ aurantium L.) has been reported to contain furanocoumarins at concentrations comparable to GFJ (Guo, 2000; Malhotra, 2001). Seville orange juice has been shown to inhibit enteric CYP3A4 in vitro and in healthy subjects (Edwards et al., 1999; Guo, 2000; Malhotra, 2001; Penzak et al., 2002; Mouly et al., 2005). Colchicine is an oral CYP3A substrate used to prevent gout flares and relieve subsequent gout attack pain (Tateishi et al., 1997). The toxicities from colchicine-CYP3A inhibitor interactions can lead to multiple-organ system failure. The effect of Seville orange juice on colchicine PK was examined in healthy volunteers (Wason et al., 2011). A single dose of colchicine $(0.6 \mathrm{mg}$ ) was administered after a four day regimen of undiluted Seville orange juice ( $240 \mathrm{~mL}$ given twice daily).

Unexpectedly, Seville orange juice decreased mean AUC of colchicine by $20 \%$ and delayed $t_{\max }$ by one hour $(\mathrm{p}<0.0001)$ relative to water. The reduced exposure may be explained by inhibition of uptake in the intestine (see Section 4.3); however, colchicine has not been evaluated as a substrate for any uptake transport protein. This interaction is not likely to be of clinical concern, as the Seville orange is rarely consumed raw, even as juice, because of the extremely sour taste. The greatest use of Seville oranges as food is in the form of marmalade (Paine and Oberlies, 2007), but no controlled clinical studies on the effects of Seville orange marmalade consumption on drug disposition have been reported. 
Pomegranate juice: The pomegranate (Punica granatum L.) continues as a popular 'superfood' touted for having high antioxidant content and disease prevention properties (Tzulker et al., 2007). The effect of pomegranate juice on CYP3A-mediated carbamazepine metabolism was studied in human liver microsomes and in rats; results suggested pomegranate juice inhibited intestinal, but not hepatic, CYP3A activity (Hidaka et al., 2005). A clinical study involving 13 healthy men given pomegranate juice $(240 \mathrm{~mL})$ and a single oral dose of midazolam $(6 \mathrm{mg}$ ) suggested lack of clinical significance (Farkas et al., 2007). A more recent study involving 16 healthy Japanese volunteers evaluated the effect of repeated pomegranate juice consumption on the CYP3A-mediated metabolism of midazolam (Misaka et al., 2011). Each subject was randomized to receive either water or a commercially available normal strength pomegranate juice $(200 \mathrm{~mL})$ twice daily for two weeks. On day 14 , midazolam $(15 \mu \mathrm{g} / \mathrm{kg})$ was administered orally with pomegranate juice or water. Relative to water, pomegranate juice did not significantly alter midazolam PK ( $\mathrm{p}=$ 0.40). Repeated consumption of pomegranate juice may not cause a clinically relevant interaction with midazolam. However, like previous clinical studies with pomegranate juice, no information was provided about the composition of the test juice. Therefore, generalizations about the enteric CYP3A inhibition potential of pomegranate juice are premature.

Tomato juice: The tomato fruit (Solanum lycopersicum L.) is consumed in many ways raw, cooked, and in drinks. The antioxidant potency and purported anticancer properties are attributable to the rich content of lycopene, a carotene and carotenoid pigment. A recent in vitro study using recombinant CYP3A4 showed that tomato juice contains one or more mechanism-based and competitive inhibitor(s) of CYP3A4 (Sunaga et al., 2011). Ethyl acetate extracts of three commercially available, additive-free tomato juices (A, B, and C) and homogenized fresh tomato were evaluated as inhibitors of testosterone $6 \beta$-hydroxylase activity in recombinant CYP3A4. Relative to control (absence of extract), all four extracts at $1.5 \%$ (3.75 $\mu \mathrm{L}$ extract in $250 \mu \mathrm{L}$ of incubation mixture) inhibited activity by $\sim 70-85 \%$; tomato juice $\mathrm{C}$ also inhibited nifedipine oxidation and midazolam $1^{\prime}$-hydroxylation activities by 80 and $63 \%$, respectively. The tomato juice $\mathrm{C}$ extract showed irreversible doseand time-dependent, as well as partial nicotinamide adenine dinucleotide phosphatedependent, inhibition of testosterone $6 \beta$-hydroxylation. Lycopene was tested at a concentration corresponding to that in tomato juice $\mathrm{C}(110 \mu \mathrm{g} / \mathrm{mL}$ of juice) but had a modest, insignificant effect (28\% inhibition). The clinical significance of CYP3A4 inhibition by tomato juice has not been determined. Interestingly, tomato juice has been studied as a 'vehicle' for administering granules of the proton pump inhibitor lansoprazole (Chun et al., 2002). Lansoprazole is metabolized by CYP2C19 and CYP3A. A randomized, four-period crossover study involving 20 healthy volunteers compared the relative oral bioavailability of lansoprazole granules administered in two juices (orange juice and tomato juice, $180 \mathrm{~mL}$ each) and a soft food (strained pears, $15 \mathrm{~mL}$ ) with that of the intact capsule $(30 \mathrm{mg})$ administered with water $(180 \mathrm{~mL})$. No differences between treatments were observed, probably because the study was not designed to evaluate the inhibitory effect of tomato juice on CYP3A. That is, lansoprazole is not an established CYP3A probe substrate, and the tomato juice product was not characterized prior to use. The possibility of a fooddrug interaction between tomato juice and appropriate CYP3A substrates warrants further examination in vivo.

Tea: Tea is the most widely consumed beverage in the world, second only to water (Dreosti, 1996; Vinson et al., 2004). The processing technique for the leaves of the tea plant (Camellia sinensis (L.) Kuntze) dictates the level of fermentation and type of tea - white, green, black, oolong, etc. (Sang et al., 2011). Green tea undergoes minimal oxidation during processing, ensuring high polyphenol content (Colalto, 2010). The predominant 
polyphenolic compounds are catechins, which are presumed to prevent and/or treat cancer, cardiovascular disease, and obesity (Antonello et al., 2007). In addition to conventional tea infusion, concentrated green tea extract prepared in oral capsule form is sold as a dietary supplement and has become a popular option for consumers. The majority of controlled clinical studies to date evaluating the effect of repeated green tea administration (given as extract) on CYP activity has not demonstrated clinically significant interactions (Donovan et al., 2004; Chow et al., 2006). However, a recent case report described a $\sim$ two-fold increase in tacrolimus levels observed in a 58 year-old kidney transplant recipient who ingested green tea while receiving tacrolimus (Vischini et al., 2011). Levels decreased to within the therapeutic range after discontinuation of the tea. In vitro and clinical studies investigating further this potential interaction have not been published. A study in rats evaluating the effect of daily green tea consumption on 5-fluorouracil PK showed green tea $(50 \mathrm{mg} / \mathrm{kg}$ for four weeks) increased the AUC of 5-fluorouracil by 425\% relative to saline (Qiao et al., 2011). Larger clinical studies are needed to determine the clinical significance of these observations.

Alcoholic beverages: Growing evidence supporting cardioprotective benefits promotes moderate alcohol consumption as part of a healthy lifestyle. Alcoholic drinks such as wine and beer can alter CYP activity via mechanisms that are independent of ethanol (Jang and Harris, 2007). Wine and beer are rich in flavonoids and other polyphenols that have antioxidant properties (Krenz and Korthuis, 2012).

Red wine: A handful of clinical drug interaction studies with red wine made from the common grape (Vitis vinifera L.) have been reported, but results have been inconsistent or clinically insignificant (Bailey et al, 2003). The magnitude of effect of red wine on the PK of CYP3A substrates may depend on both the amount and type of red wine consumed. Differentiating the effects of ethanol and wine components also poses a challenge. The red wine components trans-resveratrol (Piver et al., 2001) and gallic acid (Stupans et al., 2002) have been shown to inhibit hepatic CYP3A in vitro in a mechanism-based and noncompetitive, reversible manner, respectively. However, studies on enteric inhibition are lacking.

Beer: Beer contains many classes of compounds, including phenolic acids, $\alpha$ - and $\beta$-hop acids, and prenylflavonoids (Vinson et al., 2003). Some of these compounds have been detected in the flowers of the hops plant (Humulus lupulus $\mathrm{L}$.), which are used primarily for flavoring and preserving beer (Huvaere et al., 2003). Due to the resemblance to other plantderived antioxidants and ability to inhibit CYPs that activate carcinogens, hops constituents have been studied for their chemopreventive properties. The prenylflavonoids isoxanthohumol and 8-prenylnaringenin, as well as the prenylated chalcone xanthohumol, were weak inhibitors (at a concentration of $10 \mu \mathrm{M}$ ) of nifedipine oxidase activity in recombinant CYP3A4 (data not shown in publication) (Henderson et al., 2000). The inhibitory effect of a wide range of ales, lagers, specialty beers, ciders, and non-alcoholic lagers representative of Canadian and international markets was evaluated using recombinant CYP systems (Foster et al., 2009; Foster et al., 2011). Major a-hop acids (e.g., cohumulone, humulone, adhumulone) and $\beta$-hop acids (e.g., colupulone, lupulone, adlupulone) were measured in each product, and a wide variation in contents of alcohol and hop acids was detected. Two porter ale products $(10 \mu \mathrm{L}$ in $200 \mu \mathrm{L}$ incubation mixture, stock concentration not specified) inhibited CYP3A4-mediated dibenzylfluorescein metabolism by up to $78 \%$. A definitive relationship between inhibition and hops constituent levels could not be established. Further studies with individual compounds are warranted to support clinical evaluation. 
4.1.2. Esterase-Esterases are essential to prodrugs (e.g., enalapril, lovastatin) requiring activation via hydrolytic cleavage of the ester bond to form the active species (Patchett, 1984; Sabra, 1988). Major esterases include carboxylesterase, acetylcholinesterase, butyrylcholinesterase, paraoxonase, and arylesterase. Inhibition of enteric esterase activity by GFJ in rats has been shown to increase stability of the ester in the lumen and enterocytes, resulting in higher absorption of the ester and higher exposure to active metabolite via rapid hydrolysis in plasma (Liederer and Borchardt, 2006). The clinical significance of esterase inhibition by GFJ is under investigation.

Grapefruit juice: Clopidogrel is an oral antiplatelet prodrug that is transformed in vivo to both an inactive metabolite via esterases and an active form through a series of reactions mediated by CYP1A2, CYP2B6, CYP2C9, CYP2C19, and CYP3A4 (Kazui et al., 2010). Clopidogrel is hydrolyzed by esterases to an inactive carboxylic acid derivative that accounts for $85 \%$ of circulating metabolites in plasma (Clarke and Waskell, 2003). An ongoing clinical study (ClinicalTrials.gov Identifier: NCT00817999) is evaluating the impact of GFJ on clopidogrel loading and maintenance doses on platelet aggregation inhibition in healthy volunteers. This randomized two-way crossover study requires subjects to receive either water or single strength GFJ $(325 \mathrm{~mL})$ two hours prior to the loading dose $(300 \mathrm{mg}$ ) of clopidogrel. Subjects return six hours after the loading dose to have platelet inhibition measured. A two-week washout period allows for platelet aggregation to return to baseline. The study was projected to be completed in January 2012; results await publication.

\subsection{Phase II conjugation}

4.2.1. Uridine diphosphate glucuronosyltransferase-Human glucuronosyl transferases (UGTs) facilitate elimination of endogenous substrates and xenobiotics by increasing hydrophilicity via formation of glucuronide conjugates (Burchell et al., 1995). In general, the UGTs are bound to the endoplasmic reticulum, and substrate binding sites are exposed to the lumen (Meech and Mackenzie, 1997; Radominska-Pandya et al., 1999). UGTs are divided into two families, UGT1 and UGT2, which encompass more than 20 enzymes (Burchell et al., 1998). The identification of UGTs in human small intestine has been studied using a variety of approaches at different biochemical levels, from mRNA to protein to enzymatic activity. The expression of a relatively small number of UGTs has been confirmed in multiple laboratories using the same or different approaches - UGT1A1, UGT1A3, UGT1A8, UGT1A10, and UGT2B7 (Ritter, 2007). In contrast, analyses of several other UGTs (e.g., $-1 \mathrm{~A} 4,-1 \mathrm{~A} 6,-1 \mathrm{~A} 7,-1 \mathrm{~A} 9,-2 \mathrm{~B} 4,-2 \mathrm{~B} 10,-2 \mathrm{~B} 15)$ have produced conflicting results, which require further study to be resolved. The emergence of liquid chromatography-tandem mass spectrometry methods for absolute protein quantification may fill in the knowledge gap (Harbourt et al., 2012). Intestinal UGTs can act to limit the oral bioavailability of many botanically-derived products. Although clinical beverage-drug interactions mediated by intestinal UGTs have not been reported to date, the effect of diet on UGT activity in humans is discussed, as evidence supports dietary and genetic effects on UGT activity in humans (van der Logt, 2003; Peterson et al., 2005; Chang et al., 2007).

UGT1A1 glucuronidates bilirubin, estrogens, and several dietary carcinogens (Fisher et al., 2001). Cancer chemoprevention from dietary substances occurs partly through up-regulation of UGTs. Serum bilirubin, a marker of UGT1A1 activity, was shown previously to be lower among individuals homozygous for the UGT1A1*28 variant alleles (7/7) when randomized to a high fruit and vegetable diet (Chang et al., 2007). In a follow-up study, healthy men ( $\mathrm{n}=$ $146)$ and women $(n=147)$ provided blood samples for genotyping and bilirubin measurements (Saracino et al., 2009). Multiple linear regression was used to assess relationships among UGT1A1 genotype, bilirubin concentrations, and foods known to 
induce UGT activity (e.g., cruciferous vegetables, citrus fruits, soy foods) based on threeday eating records. A significant interaction of UGT1A1 genotype and citrus consumption among women was observed. Women with the $7 / 7$ genotype who consumed $\searrow 0.5$ daily servings of citrus fruit had $\sim 30 \%$ lower serum bilirubin than those with the same genotype who consumed less. These results suggested that citrus consumption may increase UGT1A1 activity among women with the $7 / 7$ genotype, potentially improving clearance of certain carcinogens and influencing cancer susceptibility.

Chemoprevention by isothiocyanates from cruciferous vegetables occurs partly through induction of UGTs. In a randomized, controlled, crossover feeding trial in humans $(n=70)$, three test cruciferous-based diets were compared to a fruit-and-vegetable-free basal diet (Navarro et al., 2009). Subjects were genotyped $(* 1 / * 1, * 1 / * 28, * 28 / * 28)$, and serum bilirubin was measured to assess UGT1A1 activity. Aggregate bilirubin response to all cruciferous-containing diets was lower compared to the basal diet ( $\mathrm{p}<0.03$ for all). For the UGT1A1*28/*28 genotype, lower bilirubin concentrations were noted in all cruciferouscontaining diets compared to baseline ( $p<0.02$ for all). These results may have implications for altering metabolism of both carcinogens and drugs through dietary intervention, particularly among $U G T 1 A 1 * 28 / * 28$ individuals.

Acetaminophen (APAP) glucuronidation is believed to occur mainly by UGT1A. Evidence suggests that UGT2B15 also may be important. A feeding trial was conducted to assess UGT1A6 and UGT2B15 polymorphisms and acetaminophen conjugation in response to a randomized, controlled diet of selected fruits and vegetables known to induce UGTs (e.g., cruciferous, soy, and citrus) (Navarro et al., 2011). Subjects were genotyped for $U G T 1 A 1 * 28, U G T 1 A 6^{*} 2$, and $U G T 2 B 15 * 2$. Healthy adults $(\mathrm{n}=66)$ received APAP $(1 \mathrm{~g})$ on days 7 and 14 of each two-week feeding period. Saliva and urine were collected over 12 hours. A modest relationship between UGT1A6, diet, and APAP conjugation was observed. Although the effect of the $U G T 2 B 15^{*} 2$ polymorphism on APAP glucuronidation was statistically significant, differences in APAP glucuronidation between genotypes in response to diet were small. Although larger than previous controlled feeding studies designed to evaluate effects of diet on glucuronidation, the sample size was not powered to detect genotype-diet interactions.

The inhibitory effects of commonly used herbal extracts on UGT1A4, 1A6, and 1A9 activities were evaluated in human liver microsomes (Mohamed and Frye, 2011). The green tea constituent epigallocatechin gallate (EGCG), extracted from a green tea product, inhibited UGT1A4 activity $\left(\mathrm{IC}_{50}=33.8 \pm 3.1 \mu \mathrm{g} / \mathrm{mL}\right)$. UGT1A4 has been detected in the intestine (Laverdière et al., 2011), but green tea has not been evaluated as an intestinal UGT1A4 inhibitor in vitro and in humans. Further studies are warranted.

4.2.2. Sulfotransferase-Sulfotransferases (SULTs) catalyze the sulfation of a multitude of xenobiotics, hormones (i.e., thyroid, estrogens), and neurotransmitters via conjugation with 3'-phosphoadenosine 5' -phosphosulfate (Klaassen and Boles, 1997). Three human SULT subfamilies have been identified and detected in liver, brain, intestine, lung, kidney, and other tissues (Gamage et al., 2006). SULT1As are critical protectants from xenobiotics and ingested catecholamine precursors (Harris and Waring, 2008). Molecules such as tyrosine and dopamine are sulfated preferentially by SULT1A3. Grapefruit and orange juices, as well as green tea, have been shown to inhibit two members of the SULT1 family in vitro, SULT1A1 and SULT1A3, the latter of which is expressed only in extrahepatic tissues, including the intestine (Coughtrie and Johnston, 2001; Nishimuta et al., 2005; Nishimuta et al., 2007). SULT1A inhibition prevents normal catecholamine deactivation. Like the UGTs, clinical food-drug interactions mediated by intestinal SULTs have not been reported to date, but the effect of SULT inhibitors in the diet (e.g., flavonoids in citrus fruits, 
wine, tea, chocolate) on circulating catecholamines has been explored. A recent analysis of 19 published human studies showed that ingestion of SULT1A inhibitors, such as coffee (including decaffeinated), tea, chocolate, bananas, and citrus fruits can elicit catecholamine increases, blood pressure changes, migraine headaches, and/or atrial fibrillation in susceptible individuals (Eagle, 2012). Although diet-induced SULT1A inhibition has been shown to have serious health consequences, the impact of concomitant drug intake on this complex interaction is unknown. Controlled clinical studies with appropriate SULT substrates are needed.

\subsection{Transporter-mediated efflux and uptake}

4.3.1. P-glycoprotein-Inhibition of efflux transporters can lead to altered systemic and local drug concentrations. Due to the location of the efflux transporter P-glycoprotein (P-gp) on the apical (lumenal) membrane of enterocytes (Fig. 1), substrates are extruded back into the intestinal lumen, lowering systemic drug concentrations (Huang et al., 2010). Thus, as with CYP3A, inhibition of enteric P-gp would be expected to increase systemic drug exposure. In vitro studies have demonstrated inhibition of P-gp activity by citrus juices, but the clinical relevance of enteric P-gp is dubious. Whether GFJ inhibits intestinal P-gp activity in vivo has not been fully established, largely because an ideal P-gp probe substrate has not been identified. Several drugs transported by P-gp are metabolized by CYP3A as well (Benet, 2009), making it difficult to determine causality when plasma levels of a dual CYP3A/P-gp substrate are elevated post-GFJ ingestion.

4.3.2. Organic anion transporting polypeptide-The attempt to establish an in vivo probe for P-gp activity inadvertently gave rise to a new area of food-drug interaction studies. The initial clinical study examining effects of fruit juices on enteric P-gp activity using fexofenadine as a probe substrate showed an unexpected 63\% decrease in fexofenadine AUC relative to water (Dresser et al., 2002). Mean elimination half-life was unchanged. This atypical interaction was attributed to inhibition of an apically located intestinal uptake transporter. Organic anion transporting polypeptides (OATPs) are transmembrane transport proteins that facilitate uptake of a number of endogenous compounds (e.g., bile acids, hormones) and drugs (Hagenbuch and Gui, 2008). Of the 11 human OATP family members, OATP1A2 and OATP2B1 have been reported to be expressed on apical membranes of enterocytes (Kim, 2003) (Fig. 1). Fruit juice inhibition of intestinal uptake transport has been reviewed (Greenblatt, 2009; Bailey, 2010), but new studies have been reported.

Grapefruit juice: Aliskiren is a direct renin inhibitor indicated for the treatment of hypertension. A clinical study of 11 healthy volunteers administered GFJ ( $200 \mathrm{~mL}$ singlestrength three times daily for five days) and aliskiren ( $150 \mathrm{mg}$ on day 3 ) showed that relative to water, GFJ significantly reduced mean aliskiren AUC by $61 \%$ with no change in half-life, consistent with inhibition of intestinal but not hepatic OATPs (Niemi et al., 2010). A similar study with 28 healthy subjects receiving $300 \mathrm{mg}$ aliskiren and either water or grapefruit juice ( $300 \mathrm{~mL}$ ) showed a mean AUC decrease of $38 \%$ by GFJ (Rebello et al., 2011). Accompanying in vitro studies in human embryonic kidney 293 cells expressing OATP1A2 and OATP2B1 demonstrated that aliskiren was not taken up in OATP2B1-expressing cells, indicating aliskiren is not a substrate for OATP2B1. However, uptake of $\left[{ }^{14} \mathrm{C}\right]$-aliskiren was linear in OATP1A2-expressing cells and was reduced by the citrus fruit flavonoid naringin. The $\mathrm{IC}_{50}$ averaged $75 \mu \mathrm{M}$, which is well below the reported range of concentrations in grapefruit juice (170 $\mu \mathrm{M}-6.5 \mathrm{mM}$ ) (Ho et al., 2000; Ross et al., 2000; DeCastro et al., 2006; Wanwimolruk and Marquez, 2006; Brill et al., 2009), supporting naringin as a candidate inhibitor of intestinal OATP. The clinical impact of the GFJ-aliskiren interaction may be minimal in view of interim results of the Aliskiren Trial in Type 2 Diabetes Using Cardio-Renal Endpoints (ALTITUDE) (Parving et al., 2009). Safety warnings 
recommending discontinuation of aliskiren in patients with type 2 diabetes, renal impairment, and/or cardiovascular disease have been issued due to potential risks of renal and cardiac adverse events (http://www.pharma.us.novartis.com).

Celiprolol is a cardioselective $\beta$-adrenergic receptor blocker that has been shown to interact with GFJ (Lilja et al., 2003). One of the explanations for the observed 85\% decrease in mean AUC was inhibition of celiprolol absorption in the intestine by GFJ. An uptake study in Xenopus laevis oocytes injected with either OATP1A2 or OATP2B1 cRNA showed that celiprolol was a substrate of OATP1A2 but not OATP2B1 (Kato et al., 2009). In contrast, the authors of a more recent clinical interaction study hypothesized that celiprolol was transported by intestinal OATP2B1 (Ieiri et al., 2011), partly because the intestinal expression of OATP2B1 is higher than that of other OATP isoforms (Sai et al., 2006; Meier et al., 2007). Before the human study was initiated, the authors performed an in vitro study in OATP2B1-expressing oocytes, demonstrating that celiprolol was transported by OATP2B1. The potential importance of pharmacogenomics led the authors to evaluate the contribution of $S L C O 2 B 1$ polymorphisms to celiprolol $\mathrm{PK}$ and to investigate the interaction between celiprolol and GFJ. Healthy men $(\mathrm{n}=30)$ ingested $200 \mathrm{~mL}$ of GFJ three times daily for two days. On day 3, celiprolol (100 mg) was administered with $200 \mathrm{~mL}$ of GFJ. Additional GFJ $(200 \mathrm{~mL})$ was administered at 30 minutes and 1.5 hours thereafter. The

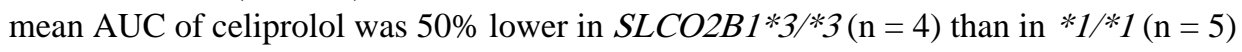
individuals but was not deemed significant $(\mathrm{p}=0.10)$. GFJ reduced mean AUC of celiprolol by up to $86 \%$ ( $\mathrm{p}<0.01$ ) compared to water, but $S L C O 2 B 1 * 3$ genotype-dependent differences in the PK profiles of celiprolol disappeared in the interaction phase. Although a population PK analysis showed $S L C O 2 B 1$ status to be a statistically significant predictor of celiprolol PK, a larger trial is needed to confirm the clinical impact of the $S L C O 2 B 1 * 3$ polymorphism.

The clinical significance of the $S L C O 2 B 1 * 3$ polymorphism has been investigated for the leukotriene receptor antagonist montelukast, which is prescribed to control asthma symptoms in adults (Mougey et al., 2009) and children (Mougey et al., 2011). In vitro experiments with Madin-Darby Canine Kidney Type II cells stably expressing OATP2B1 and Caco-2 cell lines showed that montelukast was a substrate for both OATP1A2 and OATP2B1 (Mougey et al., 2009). The PK and PD of a single dose of montelukast with and without GFJ were evaluated in adolescents and young adults (15-18 years old) with asthma (Mougey et al., 2011). The $S L C O 2 B 1 * 3$ polymorphism was expected to be associated with reduced absorption of montelukast, and co-ingestion of GFJ was hypothesized to decrease absorption of montelukast through inhibition of OATP2B1. Study volunteers $(n=26)$ were given montelukast $\left(10 \mathrm{mg}\right.$ ) with $240 \mathrm{~mL}$ of either Gatorade ${ }^{\circledR}$ (control), $4 \mathrm{X}$ concentrated GFJ, normal-strength GFJ, or normal-strength orange juice. A majority of the volunteers were $S L C O 2 B 1 * 3 / * 3(\mathrm{n}=21)$, while the remainder was $S L C O 2 B 1 * 1 / * 3(\mathrm{n}=5)$. GFJ, $4 \mathrm{X}$ GFJ, and orange juice decreased montelukast mean AUC by $7 \%, 8 \%$, and $20 \%$, respectively, compared to control. The reduction in mean AUC with orange juice co-ingestion in $S L C O 2 B 1 * 3 / * 3$ individuals was considered significant $(\mathrm{p}=0.032) . S L C O 2 B 1 * 1 * 3$ individuals showed a mean AUC reduction of $37 \%\left(\mathrm{p}=2 \times 10^{-5}\right)$ compared to the $* 1 / * 3$ group, independent of treatment. Despite significant PK findings, neither genotype nor coingestion of citrus juice had an effect on montelukast PD (data not shown in publication). However, the sample size was not justified, so the study design may have lacked sufficient power to detect an interaction. The interpretation of montelukast-SLCO2B1 studies has been questioned by the manufacturer (Merck \& Co., Inc.) (Chu et al., 2012). A series of in vitro OATP2B1-related transport experiments demonstrated that there was no direct evidence indicating that montelukast is a substrate of OATP2B1 or that a $S L C O 2 B 1$ polymorphism alters montelukast uptake. OATP1A2-mediated uptake of montelukast was not discussed. Based on the conflicting evidence, conclusions on the direct involvement of OATP2B1 in 
the absorption of montelukast are premature, and larger trials are needed to demonstrate reproducibility of the clinical observations.

Orange juice: The sweet orange (Citrus $\mathrm{x}$ sinensis (L.) Osbeck) is considered fairly innocuous due to the lack of CYP3A-inhibiting furanocoumarins in the fruit. However, clinical studies with fexofenadine, certain $\beta$-blockers, and fluoroquinolones have demonstrated that orange juice can reduce systemic exposure by up to $83 \%$ (Dresser et al., 2002; Lilja et al., 2005; Lilja 2004; Neuhofel et al., 2002; Wallace et al., 2003). Some of these interactions have been shown in vitro to involve inhibition of enteric OATP by orange juice (Dresser et al., 2002; Maeda et al., 2007; Kato et al., 2009). The effect of orange juice on aliskiren PK and PD has been investigated (Tapaninen et al, 2011). In a randomized crossover study, 12 healthy volunteers ingested $200 \mathrm{~mL}$ of orange juice, apple juice, or water three times daily for five days. On day 3, they ingested a single $150 \mathrm{mg}$ dose of aliskiren. Orange juice reduced aliskiren geometric mean AUC by $62 \%$ relative to water while having no effect on elimination half-life. Plasma renin activity was increased significantly $(\mathrm{p}=0.037)$ in the juice phase, but changes in blood pressure and heart rate were not detected. The subjects were genotyped for $S L C O 2 B 1$ polymorphisms, but no differences in aliskiren PK between the groups were observed. As discussed previously, aliskiren is not a substrate of OATP2B1. The effect of orange juice on OATP1A2-mediated aliskiren transport has not been examined in vitro, but naringin, an ingredient in orange juice (and other citrus fruits), has been shown to reduce aliskiren uptake (Rebello et al., 2011).

Apple juice: The consumption of apples (Malus $x$ domestica Borkh.) has been linked to reduced risk of some cancers, cardiovascular disease, asthma, and diabetes (Gerhauser, 2008). Main structural classes of apple constituents include hydroxycinnamic acids, dihydrochalcones, flavan-3-ols, flavonols, and triterpenoids. While there have been no in vitro and clinical studies investigating the effect of apple juice on drug metabolism, evidence exists that apple juice inhibits OATP activity in vitro (Satoh et al., 2005) and in human volunteers (Dresser et al., 2002). The following clinical studies involving apple juice address growing attempts to elucidate the pharmacogenomic impact of drug transport proteins.

The effects of the $S L C O 2 B 1 * 3$ variant (c.1457C>T) and concomitant apple juice intake on fexofenadine and midazolam oral PK were evaluated in a randomized crossover study of 14 healthy volunteers (Imanaga et al., 2011). Individuals were divided based on genotype - CC $(\mathrm{n}=5)$, CT $(\mathrm{n}=5)$, TT $(\mathrm{n}=4)$. Fexofenadine $(60 \mathrm{mg})$ and midazolam $(5 \mathrm{mg})$ were administered with $300 \mathrm{~mL}$ of either water or normal-strength apple juice (reconstituted from concentrate). Additional juice was administered post-dose (150 mL every 30 minutes for 3 hours; total volume $=1.2 \mathrm{~L})$. When the genotyped groups were stratified in the water phase, subjects with CT and TT alleles showed a 37\% decrease $(\mathrm{p}<0.05)$ in fexofenadine mean AUC compared to those with CC alleles. Regardless of genotype, apple juice decreased fexofenadine mean AUC by $79 \%$ ( $p<0.05$ ) relative to water. Neither the genotype nor the apple juice showed significant effects on the PK of midazolam, indicating that apple juice had minimal effect on CYP3A activity. OATP-mediated uptake of fexofenadine was evaluated in Xenopus laevis oocytes expressing OATP2B1 and was shown to be three-fold higher $(\mathrm{p}<0.05)$ than that by water-injected oocytes, indicating that fexofenadine was a substrate of OATP2B1. Some studies have shown that fexofenadine is transported by OATP2B1 (Mougey et al., 2009; Ieiri et al., 2011, Ming et al., 2011), but others have not (Glaeser et al., 2007; Mandery et al., 2010). Although the clinical study results are consistent with previous findings, the impact of the OATP2B1 polymorphism is uncertain given the small sample size. 
A recently reported clinical study demonstrated that apple juice, like orange juice (Lilja et al., 2005), reduced plasma concentrations of the $\beta$-blocker atenolol (Jeon et al., 2012). The effect of apple juice, as well as $S L C O 2 B 1$ c.1457C $>$ T polymorphism, on atenolol PK was determined by a three-way crossover study of 12 healthy volunteers. Individuals were divided based on genotype - CC $(n=6)$ and TT $(n=6)$. Subjects ingested atenolol $(50 \mathrm{mg})$ with either water or apple juice $(300 \mathrm{~mL})$ in the first phase and additional apple juice in the second $(900 \mathrm{~mL})$ and third $(300 \mathrm{~mL})$ phases. Blood pressure and heart rate were measured up to 48 hours after dosing. Apple juice $(1.2 \mathrm{~L})$ reduced atenolol mean AUC by up to $86 \%$ ( $p<0.001)$. Genotype did not affect atenolol PK. No significant differences were observed in the hemodynamic variables. The mechanism of this interaction has not been elucidated. Atenolol has been identified as a substrate of OATP1A2 in an in vitro study of Xenopus laevis oocytes (Kato et al., 2009), but the effect of apple juice (and orange juice) has not been assessed. Although no changes in PD outcomes were observed in healthy volunteers, the apple juice-atenolol interaction may be significant in cardiovascular disease patients.

Tea: Green tea is characterized by high concentrations of catechins, including EGCG, epicatechin (EC), epigallocatechin (EGC), and epicatechin gallate (ECG). The predominant catechin, EGCG, has been studied extensively for purported health benefits (Zaveri, 2006). The effects of the four catechins on OATP1A2 and OATP2B1 activity have been evaluated in vitro. Both EGCG and ECG at $100 \mu \mathrm{M}$ inhibited OATP2B1-mediated estrone-3-sulfate uptake by $\sim 70 \%$ (Fuchikami et al., 2006; Roth et al., 2011), with ECG showing higher potency than EGCG (IC 50 of $36 \mathrm{vs.} 100 \mu \mathrm{M}$ ) (Roth et al., 2011). EGCG and ECG (both at $100 \mu \mathrm{M}$ ) also inhibited OATP1A2-mediated estrone-3-sulfate uptake by $~ 75 \%$, with ECG again showing higher potency than EGCG ( $\mathrm{IC}_{50}$ of $10 \mathrm{vs.} 55 \mu \mathrm{M}$ ) (Roth et al., 2011). ECG and EGCG concentrations in brewed green tea average $450 \mu \mathrm{M}$ and $430 \mu \mathrm{M}$, respectively, with maximum concentrations of each catechin in the low millimolar range (http:// www.nal.usda.gov). Consumption of a cup (e.g., 240-300 mL) or two of green tea would result in intestinal concentrations of ECG and EGCG within the range that inhibits OATP activity. However, the clinical significance of intestinal OATP inhibition by green tea has not been investigated.

\section{Challenges in establishing clinical significance}

A number of botanically-derived beverages have been shown to inhibit several intestinal CYPs and transporters in vitro, but many of the interactions have not translated to the clinic. These in vitro-in vivo discordances may be due to a lack of sufficient and/or quality data to determine a true positive interaction (Table 2). Although this review is focused on beveragedrug interactions and associated mechanisms, the proceeding concepts and recommendations for how to advance research strategies and standards in this field can be applied, in general, to any botanically-derived product-drug interactions.

\subsection{Methods to improve research practices}

Clinical dietary substance-drug interaction studies can be confounded easily by the documented variability of specific constituents (known and unknown) in individual foods. Some in vitro-in vivo discrepancies can be addressed simply by improved documentation of the botanical source material's origin(s); others may require more rigorous experimental investigation (e.g., discerning additive, synergistic, or inhibitory effects of constituents). Many clinical studies in the literature are incomplete, flawed, or superficial. Strict peer review of relevant manuscripts is essential to promoting best practices. A checklist of recommended questions to consider when evaluating submitted research articles or already published literature is listed in Table 3. Robust, systematic methods for evaluating potential 
dietary substance-drug interactions are critical, as one of the ultimate goals is to establish a framework for the quantitative prediction of food-drug interactions.

\subsubsection{Identification and characterization of causative ingredients-A}

fundamental deficiency common to most dietary substance-drug interaction studies is limited or no descriptions of the chemical composition of the food product. The concentration of putative ingredients might not be sufficient to inhibit metabolism/transport in vivo (Farkas and Greenblatt, 2008). Since beverages are derived from single or multiple botanical sources, they are composed of complex mixtures of numerous phytochemical entities (Visioli et al., 2011). The sources and complexity of a plant's chemical constituents can contribute to batch-to-batch inconsistency, as concentrations of bioactive compounds can be affected by ecology, cultivation and manufacturing practices, storage conditions, and other environmental factors (De Castro et al., 2006). Thus, testing a random product in vitro and in vivo without evaluating the chemical makeup provides no basis for comparison between studies. Documentation and reporting of dietary substance characterization must be improved because many clinical studies lack thorough information about the test product. For commercially available products, the brand name, manufacturer, lot number, ingredients, preparation directions, and manufacturing process should be stated at minimum (Dentali, 2010). For freshly prepared material, scientific name, quantity, plant part used, collection site, preparation procedures, and storage conditions should be noted. Following verification of the test material, identification of components responsible for metabolism- or transport-mediated interactions poses the next challenge.

Thorough characterization of constituents is a difficult but essential task, and advances in analytical detection technologies have improved the efficiency and sensitivity with which active constituents have been identified. The resulting 'marker' compound(s) can be used to authenticate the test product, serving as an indicator of quality and potency in terms of standardization (Smillie and Khan, 2010). Since administration of 'standardized' foods is not possible, it would be more realistic to quantify a particular known/suspected component, or group of components, prior to clinical use. This practice would allow some degree of between-study comparison, as terms such as 'normal,' 'regular,' 'single,' 'double' strength have little meaning. For drug metabolism/transport purposes, a marker compound need not be unique to a particular product. The identity of constituent(s) should be confirmed by in vitro methods that screen for potential interactions. Selection of bioassay systems and associated protocols to quantify activity should be determined by the drug(s) and relevant phytochemical species of interest (Markowitz et al., 2008). Such experiments provide mechanistic information about inhibitory capacities, as well as specific enzymes and/or transporters involved. Two examples illustrating the aforementioned approach as it applies to drug metabolism and transport are discussed (Kim et al., 2011; Roth et al., 2011).

Conflicting results from an in vivo rat study (Uesawa and Mohri, 2006) and a clinical study (Lilja et al., 2007) examining the interaction between CYP3A substrates and cranberry juice (CBJ) prompted a systematic in vitro-in vivo approach to identify a CBJ product capable of inhibiting enteric CYP3A in human volunteers (Ngo et al., 2009). The effects of five CBJ products (blinded for in vitro experiments) were evaluated on midazolam 1 '-hydroxylation activity in human intestinal microsomes. Each juice brand (ranging from concentrate to fresh pressed preparations) inhibited CYP3A activity in a concentration-dependent manner but with differing extents of inhibition, demonstrating that one brand is not representative of the broad marketplace. The most potent of these juices, CBJ ' $E$ ', was tested next in a proof-ofconcept clinical study involving 16 healthy volunteers. Each volunteer was administered juice $\mathrm{E}$ (double-strength) or water $(240 \mathrm{~mL} \times 3$, separated by $15 \mathrm{~min}$ intervals $)$ and midazolam $(5 \mathrm{mg}$ ) with the third glass of juice/water. Relative to water, CBJ increased the 
geometric mean AUC of midazolam by $\sim 30 \%$ ( $p<0.001$ ) while having no effect on geometric mean terminal half-life, suggesting inhibition of intestinal CYP3A activity.

A common approach used in the natural products field to isolate therapeutically active ingredients, bioactivity-guided fractionation, was used to identify the CYP3A inhibitors present in the clinical test CBJ (Ngo et al., 2009). The juice was partitioned into hexane-, chloroform-, butanol-, and water-soluble fractions. Each fraction was evaluated as an inhibitor of midazolam 1'-hydroxylation in human intestinal microsomes. The hexane- and chloroform-soluble fractions at $50 \mu \mathrm{g} / \mathrm{mL}$ were the most potent, inhibiting activity by 77 and $63 \%$, respectively, suggesting that the CYP3A inhibitors resided in these more lipophilic fractions. A series of bioactivity-guided fractionation studies with whole cranberry (Vaccinium macrocarpon Ait.) were initiated next to identify potential specific enteric CYP3A inhibitors in cranberry (Kim et al., 2011). Using human intestinal microsomes and recombinant CYP3A4, three triterpenes (maslinic acid, corosolic acid, ursolic acid) were isolated. $\mathrm{IC}_{50}$ values ranged from 2.8 (maslinic acid) to $<10 \mu \mathrm{M}$ (ursolic acid). Results suggested that these triterpenes may have contributed to the CBJ-midazolam interaction observed clinically. The overall approach substantiated that in vitro characterization of dietary substances is required before initiation of clinical dietary substance-drug interaction studies, one brand of a given dietary substance is not predictive of all brands, and bioactivity-guided fractionation can be used to identify specific causative bioactive ingredients.

A bioassay-directed isolation approach was applied to the subtropical shrub aratiku (Rollinia emarginata Schlecht) to identify OATP modulators (Roth et al., 2011). The stem barks of the shrub have been used in combination with yerba mate (Ilex paraguayensis St. Hilaire) as a migraine treatment and as a relaxant. Initial screening identified aratiku extract as a modulator of OATP-mediated transport. Fractions of the extract were screened in Chinese hamster ovary cells stably transfected with OATP1B1 or OATP1B3. Potential effects on OATP1B1- and OATP1B3-mediated uptake of the two model substrates, estradiol-17 $\beta$ glucuronide and estrone-3-sulfate, were evaluated. Although the in vitro experiments were intended for liver-specific OATPs, to the best of the authors' knowledge, the approach is the only one published to date that utilized bioactivity-guided fractionation to isolate modulators of drug uptake transporters. Ursolic acid, oleanolic acid, and 8-trans- $p$-coumaroyloxy- $a$ terpineol significantly inhibited estradiol-17 $\beta$-glucuronide uptake by OATP1B1 ( 70\% of DMSO control) but not OATP1B3. The $\mathrm{IC}_{50}$ values for ursolic acid and oleanolic acid were $\sim 15 \mu \mathrm{M}$ and $\sim 4 \mu \mathrm{M}$, respectively. Ursolic acid and oleanolic acid modestly inhibited estrone-3-sulfate uptake by both OATPs (by up to 40\% of control). Quercetin 3-O-a-Larabinopyranosyl $(1 \rightarrow 2)$ a -L-rhamnopyranoside strongly inhibited OATP1B1- and OATP1B3-mediated uptake of estradiol-17 $\beta$-glucuronide (by > 95\%). However, OATP1B3mediated uptake of estrone-3-sulfate was stimulated. The thorough descriptions of the starting material, preparation procedures, analytical methods, and bioassay system protocols were strengths of the work. The overall method illustrated the efficiency of bioassay-guided isolation to identify selective transporter modulators in a botanical that has not been studied clinically. Interestingly, ursolic acid also was identified in the CBJ product mentioned previously. Such information permits assumptions about which drugs may interact with a food containing ursolic acid (e.g., apple, cranberry, pear, plum, olives) (He and Liu, 2006; Aggarwal and Shishodia, 2006; Allouche, et al., 2009; Guinda, et al., 2010)

Identification and thorough characterization of a particular dietary substance does not change immediately certain research practices. Since the establishment of furanocoumarins in GFJ as unequivocal mediators of enteric CYP3A-based interactions in 2006 (Paine et al., 2006), only a handful ( $n \sim 5$ ) of clinical studies involving CYP3A substrates have reported furanocoumarin content in the test juice. Furanocoumarins have been studied to the extent 
that they can be considered marker compounds. Characterization of a given GFJ in terms of furanocoumarin content could be used to predict the likelihood and magnitude of an interaction (see Section 5.1.4). Between-study comparisons also can be made. A basic, yet overlooked, solution to establishing meaningful physiological dose-response relationships for dietary substances is to characterize the product prior to use. The information gained will inform the nature and extent of follow-up in vitro and in vivo interaction studies.

\subsubsection{Appropriate design of in vitro and in vivo food-drug interaction studies}

-The regulation (or lack thereof) of dietary substances in the United States is different from drugs. Although dietary substances are regulated as food (Abdel-Rahman et al., 2011), bioactive compounds in these substances can act like drugs (i.e., cure, mitigate, treat, or prevent disease). Since it is unlikely that legislation will change to require more intense drug-dietary substance interaction studies, individuals in the field can take a cue from the pharmaceutical industry and adopt some or all recommendations made in the FDA's guidance on drug-drug interaction studies (http://www.fda.gov/cder/guidance) to create a more consistent evaluation approach. Methods and decision trees in the guidance on botanical drug products (Chen et al., 2008) pale in comparison. As stated previously, the experimental design aimed to quantify activity of a dietary substance should be determined by the drug(s)/probe substrate(s) and relevant phytochemical constituent(s) of interest. Data generated from well-designed in vitro studies (e.g., $\mathrm{K}_{\mathrm{m}}, \mathrm{V}_{\mathrm{max}}, \mathrm{K}_{\mathrm{i}}, \mathrm{IC}_{50}$ determinations), combined with clinical PK information, may serve as a screening mechanism to rule out the need for additional in vivo studies, or provide a mechanistic basis for proper design of clinical studies using a modeling and simulation approach (see Section 5.1.4).

\subsubsection{Development and validation of PK-PD relationships-Pharmacodynamic} consequences of dietary substance-drug interactions are underexplored aspects of controlled clinical PK studies. Selection of one or more clinically relevant PD measures begins with a drug of interest for use in a target patient population. Most PD endpoints are surrogates that correlate with clinical efficacy and are assessed in multiple dosing studies conducted over a period of more than one week or months. For example, antihypertensive drug trials measure blood pressure, antihistamine studies measure skin wheal formation, antiviral agent studies measure viral load, and opioid analgesic trials record pain scores (efficacy) and pupil diameter (toxicity) (Derendorf and Hochhaus, 1995). Depending on the therapeutic drug category, some PD measures have been validated over time and are well-accepted surrogates for drug efficacy and toxicity. Most food-drug interaction trials involve single dosing of healthy volunteers, who may exhibit different PK and PD outcomes compared to diseased patients. More studies in patient populations are needed to determine the short- and longterm responses to dietary substance-drug interactions.

A recent study with GFJ and atorvastatin demonstrated the importance of measuring PD outcomes and cautious extrapolation of conclusions from short term, healthy subject trials to the actual clinical setting of drug-treated patients (Reddy et al., 2011). Previous healthy volunteer studies have shown that large quantities $(200-250 \mathrm{~mL}$ three times daily for $\geq$ two days) of GFJ increase exposure to atorvastatin by up to three-fold (Lilja et al., 1999; Fukazawa et al., 2004; Ando et al., 2005). The Grapefruit Effect on Atorvastatin Therapy (GREAT) trial evaluated the effects of a typical daily single 'dose' of GFJ on plasma concentrations and lipid-lowering effects of atorvastatin in hyperlipidemic patients on a stable atorvastatin regimen (>90 days) (Reddy et al., 2011). Patients receiving extended treatment with atorvastatin $(10,20$ or $40 \mathrm{mg}$ daily) at a stable dose were randomized to two arms and received normal strength GFJ (300 mL daily) for 90 days. One cohort (Arm A, $\mathrm{n}=$ 60) continued on their current dose of atorvastatin; the other cohort (Arm B, n = 70) reduced the daily dose by half to confirm the need for atorvastatin dosage reduction while on GFJ. Serum atorvastatin, lipid profile, liver function, and creatine phosphokinase (to monitor for 
muscle toxicity) were measured at baseline and at 30,60, and 90 days after starting GFJ. A statistically significant increase (19-26\%) in median serum atorvastatin concentration was observed in Arm A, but changes in lipid profile were negligible. No adverse effects in liver or muscle were evident. Arm B showed a decrease (12-25\%) in median serum atorvastatin with a small but statistically significant unfavorable serum lipid profile (i.e., increased cholesterol, triglycerides, low-density lipoprotein). No adverse effects on liver function tests or creatine phosphokinase were observed. Although the study results suggested chronic GFJ co-ingestion with atorvastatin is safe, several considerations should be noted. First, the lipid profile of the study population at baseline (i.e., already on stable dose of atorvastatin) was reasonably controlled, so the addition of GFJ might have been minimally effective. Patients newly prescribed atorvastatin may have a different outcome; that is, concomitant GFJ may improve the lipid profile more rapidly and/or to a greater extent than in patients stabilized on atorvastatin. Second, the lack of effect on lipids may have been due to insufficient furanocoumarin content in the test juice; the increase in atorvastatin exposure was modest. Furanocoumarin content in the test GFJ was not reported, and whether it was measured is unclear. Third, the $100 \%$ Florida GFJ used in the study was from one lot and was tested for uniformity and nutritional content (e.g., sugar, total carbohydrate, vitamin C). It is possible that the daily intake of carbohydrate and sugar in the GFJ offset some of the clinical benefit.

The aforementioned study highlights the importance of designing clinical studies that reflect typical eating/drinking habits. The study also draws attention to the potential use of dietary substances as 'PK boosters.' Indeed, deliberate inhibition of enteric CYP3A by GFJ consumption and/or individual components has been used by the scientific community for both therapeutic and pharmacoeconomic purposes. For example, this strategy has been evaluated and suggested to be beneficial to patients undergoing treatment for cancer and organ transplantation. Oral bioavailability would be increased without GFJ itself exerting additional adverse effects. Costs and side effect severity of these multi-drug and toxic regimens could be reduced through dose and/or dosing frequency reduction by coadministration with GFJ. The tyrosine kinase inhibitor imatinib, as well as the immunosuppressants sirolimus and tacrolimus, have been investigated clinically (Kimura et al. 2011; Cohen et al., 2009; Liu et al., 2009). A deficiency common to all the studies is the lack of phytochemical analysis of the juice. The clinical trial investigating the effect of GFJ on sirolimus PK in advanced solid tumor patients initially showed no effect of GFJ, which was attributed to insufficient furanocoumarin content in the selected GFJ. A more 'potent' GFJ containing (unreported) inhibitory concentrations of furanocoumarins increased plasma sirolimus concentrations by up to $400 \%$ relative to water. The clinical study evaluating the effect GFJ on imatinib PK in Japanese men diagnosed with chronic myelogenous leukemia showed no effect; furanocoumarin content in the GFJ was not measured. The lack of effect in the imatinib study could be attributed to the same reason a lack of effect was observed initially in the sirolimus study. A recent study in rats suggested that GFJ may be equally effective as ritonavir in increasing the bioavailability of the HIV protease inhibitor lopinavir (Ravi et al., 2012). Again, like the aforementioned studies, the GFJ was not analyzed for furanocoumarin content. In addition, translation of this interaction to the clinical setting has not been determined. Phytochemicals (e.g., green tea catechins) capable of inhibiting efflux transporters have been studied with anti-tumor agents as multidrug resistance-reversing cotherapies (Asensi et al., 2011; Wu et al., 2011). Long-term safety and pharmacoeconomic impact of combining drugs and dietary substances have not been evaluated sufficiently to change current disease management.

PD-related conclusions are unwarranted due to insufficient data on the PK relationship between the causative ingredient(s) and the drug(s). A rigorous evaluation of a PK-PD relationship can be achieved by applying in silico methods to in vitro and in vivo data. Modeling and simulation techniques permit the prediction of a potential interaction, but 
extensive in vitro data (e.g., physicochemical properties, ADME parameters) and clinical PK information (including external datasets for validation) are imperative.

5.1.4. Prediction of food-drug interactions-PK-PD modeling and simulation have become powerful, integral tools for improving the efficiency of the drug development process, and the value of these approaches has been championed in several reviews (Gobburu and Marroum, 2001; Chien et al., 2005; Miller et al., 2005; Holford et al., 2010). The (patho)physiology of biological systems and the pharmacology of treatments acting on these systems can be modeled to predict quantitatively the dose-response relationship. Similar principles can be applied to dietary substances, especially in relation to how they interact with drugs. A quantitative analysis of both in vitro and clinical PK data is accomplished by a variety of algorithms and models (e.g., basic, mechanistic, static, or dynamic) (Einolf, 2007). The application of physiologically-based pharmacokinetic (PBPK) modeling to drug development has evolved over the past 10 years, reflecting significant advances in the predictability of key PK parameters from in vitro and in vivo data and in the availability of specialized software (e.g., GastroPlus, Simcyp, Berkeley-Madonna, MATLAB-simulink) (Pang and Durk, 2010; Poulin et al., 2011; Rowland et al., 2011; Zhao et al., 2011; Bouzom et al., 2012). Framing the right question and capturing key assumptions are essential to delivering meaningful results. For the purpose of this review, modeling and simulation strategies as they apply to the quantitative prediction of CYP3A-mediated oral DDIs are discussed. Lessons from these approaches can be applied to dietary substance-drug interactions to establish a framework for the quantitative prediction of such interactions (Table 4).

The utility and accuracy of in vitro CYP inhibition data in the prediction of in vivo DDIs has been examined in numerous works with varying degrees of success (Galetin et al., 2005; Galetin et al., 2006; Obach et al., 2005; Obach et al., 2006; Obach et al., 2007; Houston and Galetin, 2008; Fahmi et al., 2008; Youdim et al., 2008; Obach, 2009; Fahmi et al., 2009; Fan et al., 2010; Boulenc and ., 2010; Guest et al., 2011; Shardlow et al., 2011). Most of the cited predictive models are related to hepatic CYP3A-mediated interactions since they are well-characterized and $>50 \%$ of marketed pharmaceutical agents are CYP3A substrates, allowing for validation. However, models have been modified to incorporate the contribution from the intestine, as studies demonstrated that inhibition of both hepatic and intestinal metabolism was needed for an improved DDI prediction (Galetin et al., 2007; Yang et al., 2007; Galetin et al., 2008; Galetin et al., 2010; Peters, 2008; Tachibana et al., 2010; Gertz; et al., 2010; Gertz et al., 2011; Tachibana et al., 2012). PBPK modeling is used extensively, and such a data-driven method relies on extensive information on the victim and precipitant drugs - physicochemical properties, intestinal permeability, organ clearance processes, etc. The difficulty with dietary substances is the paucity of research on their oral bioavailability, metabolic mechanisms, human PK, and concentrations achieved at the site(s) of action. Despite the challenges, evaluation of a suspected dietary substance-drug interaction is possible, and one particularly relevant to this discussion is described (Fenneteau et al., 2010).

Furanocoumarins in GFJ have been studied extensively over the past two decades years as inhibitors of CYP3A4 (intestinal and hepatic, although the latter is less relevant).

Bergamottin and $6^{\prime}, 7^{\prime}$-dihydroxybergamottin (DHB) are typically the most abundant furanocoumarins present in GFJ and have been proposed as major intestinal CYP3A4 inhibitors contributing to GFJ-drug interactions (Paine et al., 2004; Uesawa et al., 2011). These compounds have been characterized to the extent that they can be considered 'marker' compounds. Quantification of a given juice in terms of furanocoumarin content could be used to predict the likelihood and magnitude of an interaction with a CYP3A substrate and make between-study comparisons. Modeling and simulation can be used to validate one or 
more marker furanocoumarins as predictors of an interaction. As discussed previously, given the possibility of using GFJ and/or individual constituents as a 'drug-sparing, PK-boosting agent,' a standardized approach to evaluate quantitatively GFJ-drug interactions is imperative for the proper clinical management of patients.

A PBPK modeling approach was used to predict the impact of inhibiting intestinal and hepatic metabolism on human PK of CYP3A substrates (Fenneteau et al., 2010). One of the inhibitors of interest was DHB, which was given in the form of GFJ in two clinical studies (Kupferschmidt et al., 1995; Lilja et al., 2004). The objective was to predict the PK of simvastatin and midazolam in the presence of DHB in humans. A model was developed (software not specified) to account for absorption (gut), distribution, and hepatic clearance of the substrates and DHB. An important set of data to calculate parameters related to those processes is physicochemical properties of the drugs and DHB. Molecular structure, solubility, and permeability properties have been used to develop in silico models that allow the early estimation of several ADME properties. Commercial ADME software programs are reviewed elsewhere (van de Waterbeemd and Gifford, 2003). Inhibitory parameters of DHB (i.e., $\mathrm{K}_{\mathrm{i}}$ and $\mathrm{k}_{\text {inact }}$ ) measured in human intestinal microsomes and unbound DHB concentration in human intestinal microsomes were incorporated into the model. Because no plasma concentration-time profile of DHB was available (or detectable), the concentration of DHB in the gut membrane was simulated using the PBPK model. For the simulations, the authors assumed a DHB amount of $43 \mu \mathrm{mol}$. Interestingly, DHB was not measured in either of the GFJs used in the clinical studies. Nevertheless, the resulting profile was used to predict the inhibitory effect of GFJ on midazolam and simvastatin PK. AUC and maximum plasma concentration $\left(\mathrm{C}_{\max }\right)$ were predicted successfully within a two-fold error range either in the absence or presence of DHB. This PBPK study was the first to investigate the impact of an inhibitory food ingredient on drug PK. Additional studies with other substrates would validate this approach. Once validated, the techniques can be applied to other food ingredients. Although the aforementioned study was specific to CYP3A, it is important to note that food and substances in food can inhibit both uptake and efflux transporters in the intestine; the final result on drug bioavailability will depend on the more important contributor to absorption. Furthermore, the interplay between CYPs and transporters in dietary substance-drug interactions is recognized (Benet et al., 2003); thus, incorporation of more complex processes will require more detailed data. Literature examples for modeling/ predicting intestinal transporter-mediated interactions are few (Bolger et al., 2009; Fan et al., 2010).

In summary, whole body physiology is described by a series of linked mathematical equations with model parameters corresponding to measurable quantities, such as blood flow rates and tissue volumes. In vitro data relevant to drug absorption, distribution, metabolism, and excretion are scaled to in vivo scenarios. The new FDA guidance on DDI studies emphasizes the use of modeling and simulation to streamline the development process. Although such an approach is not required of those in the food/dietary supplement industries, modeling and simulation of new drug candidates and known dietary ingredients should be undertaken. This approach may rectify a considerable amount of work that may otherwise be inconsistent, contradictory, and irreproducible.

\section{Conclusions}

Interactions between medications and dietary substances, as foods or supplements, remain a relatively understudied and misunderstood area of pharmacotherapy. The upward trend of polypharmacy and ever-increasing consumer perception, rather misconception, of "allnatural" (i.e., safe) remedies from dietary supplements and so-called 'superfood' sources has contributed to the potential for dangerous interactions. Although significant progress has 
been made in understanding mechanisms of intestinal inhibition by CYPs and efflux/uptake transport proteins, questions remain. Results from in vitro studies have not always translated to the clinic; these in vitro-in vivo discordances may be due to a lack of well-designed, proof-of-concept studies that control for as many confounding factors as possible. The complex nature of dietary substances and lack of adequate characterization preclude between-study comparisons, as well as accurate predictions of drug interaction liability. Since no 'standard' system exists to predict the effect of dietary substances on drug disposition, researchers in the field can model their scientific approach after that used in drug development. The integration of data from in vitro, in vivo, and in silico studies can optimize study designs and clarify the potential risks of inhibition of intestinal metabolism/ transport by a given dietary substance on pharmacotherapeutic outcomes. Such an aggressive assessment requires a multidisciplinary collaboration of experts from several fields, including clinical pharmacologists, pharmacognosists/natural products chemists, and botanists (Dentali, 2010; Gurley, 2010). The ultimate goal is to develop practice guidelines to provide a consistent approach in managing drug-dietary substance interactions appropriately.

\section{Acknowledgments}

This work was supported in part by the National Institutes of Health (R01 GM077482). MFP dedicates this article to Dr. David P. Paine.

\section{Abbreviations}

$\begin{array}{ll}\text { APAP } & \text { acetaminophen } \\ \text { AUC } & \text { area under the curve } \\ \text { BG } & \text { bergamottin } \\ \text { bid } & \text { two times a day } \\ \text { C }_{\text {max }} & \text { maximum concentration } \\ \text { CBJ } & \text { cranberry juice } \\ \text { CYP } & \text { cytochrome P450 } \\ \text { DDI } & \text { drug-drug interaction } \\ \text { DHB } & 6^{\prime}, 7^{\prime} \text {-dihydroxybergamottin } \\ \text { FDA } & \text { Food and Drug Administration } \\ \text { EGCG } & \text { epigallocatechin gallate } \\ \text { GI } & \text { gastrointestinal } \\ \text { GFJ } & \text { grapefruit juice } \\ \text { IC } & \text { half maximal inhibitory concentration } \\ \text { K }_{\mathbf{i}} & \text { inhibition constant } \\ \mathbf{k}_{\text {inact }} & \text { maximal inactivation rate constant } \\ \text { K } & \text { substrate concentration at which reaction rate is half of } \mathrm{V}_{\text {max }} \\ \text { NC } & \text { not calculated } \\ \text { NS } & \text { not statistically significant } \\ \text { NSP } & \text { not specified } \\ & \end{array}$


OATPs organic anion transporting polypeptides

P-gp P-glycoprotein

PK pharmacokinetics

PD pharmacodynamics

SS statistically significant

SULTs sulfotransferases

$\mathbf{V}_{\max } \quad$ maximum rate

tid three times a day

\section{References}

Abdel-Rahman A, Anyangwe N, Carlacci L, Casper S, Danam RP, Enongene E, et al. The safety and regulation of natural products used as foods and food ingredients. Toxicol Sci. 2011; 123:333-348. [PubMed: 21821733]

Aggarwal BB, Shishodia S. Molecular targets of dietary agents for prevention and therapy of cancer. Biochem Pharmacol. 2006; 71:1397-1421. [PubMed: 16563357]

Agosti S, Casalino L, Bertero G, Barsotti A, Brunelli C, Morelloni S. A dangerous fruit juice. Am J Emerg Med. 2012; 30:e5-8. [PubMed: 20970282]

Allouche Y, Jiménez A, Uceda M, Aguilera MP, Gaforio JJ, Beltrán G. Triterpenic content and chemometric analysis of virgin olive oils from forty olive cultivars. J Agric Food Chem. 2009; 57:3604-3610. [PubMed: 19326867]

Ando H, Tsuruoka S, Yanagihara H, Sugimoto K, Miyata M, Yamazoe Y, et al. Effects of grapefruit juice on the pharmacokinetics of pitavastatin and atorvastatin. Br J Clin Pharmacol. 2005; 60:494497. [PubMed: 16236039]

Antonello M, Montemurro D, Bolognesi M, Di Pascoli M, Piva A, Grego F, et al. Prevention of hypertension, cardiovascular damage and endothelial dysfunction with green tea extracts. Am J Hypertens. 2007; 20:1321-1328. [PubMed: 18047924]

Asensi M, Ortega A, Mena S, Feddi F, Estrela JM. Natural polyphenols in cancer therapy. Crit Rev Clin Lab Sci. 2011; 48:197-216. [PubMed: 22141580]

Bailey DG, Dresser GK, Bend JR. Bergamottin, lime juice, and red wine as inhibitors of cytochrome P450 3A4 activity: comparison with grapefruit juice. Clin Pharmacol Ther. 2003; 73:529-537. [PubMed: 12811362]

Bailey DG, Dresser GK, Leake BF, Kim RB. Naringin is a major and selective clinical inhibitor of organic anion-transporting polypeptide 1A2 (OATP1A2) in grapefruit juice. Clin Pharmacol Ther. 2007; 81:495-502. [PubMed: 17301733]

Benet LZ. The drug transporter-metabolism alliance: uncovering and defining the interplay. Mol Pharm. 2009; 6:1631-1643. [PubMed: 19874004]

Benet LZ, Cummins CL, Wu CY. Transporter-enzyme interactions: implications for predicting drugdrug interactions from in vitro data. Curr Drug Metab. 2003; 4:393-398. [PubMed: 14529371]

Bolger MB, Lukacova V, Woltosz WS. Simulations of the nonlinear dose dependence for substrates of influx and efflux transporters in the human intestine. AAPS J. 2009; 11:353-363. [PubMed: 19434502]

Boulenc X, Barberan O. Metabolic-based drug-drug interactions prediction, recent approaches for risk assessment along drug development. Drug Metabol Drug Interact. 2011; 26:147-168. [PubMed: 22149659]

Boullata, JI.; Armenti, VT. Handbook of drug-nutrient interactions. New Jersey: Humana; 2004.

Bouzom F, Ball K, Perdaems N, Walther B. Physiologically based pharmacokinetic (PBPK) modelling tools: how to fit with our needs? Biopharm Drug Dispos. 2012; 33:55-71. [PubMed: 22228149] 
Brill S, Zimmermann C, Berger K, Drewe J, Gutmann H. In vitro interactions with repeated grapefruit juice administration-to peel or not to peel? Planta Med. 2009; 75:332-335. [PubMed: 19148864]

Brown C, Taniguchi G, Yip K. The monoamine oxidase inhibitor-tyramine interaction. J Clin Pharmacol. 1989; 29:529-532. [PubMed: 2666453]

Burchell B, Brierley CH, Rance D. Specificity of human UDP-glucuronosyltransferases and xenobiotic glucuronidation. Life Sci. 1995; 57:1819-1831. [PubMed: 7475929]

Burchell B, Brierley CH, Monaghan G, Clark DJ. The structure and function of the UDPglucuronosyltransferase gene family. Adv Pharmacol. 1998; 42:335-338. [PubMed: 9327909]

Charman WN, Porter CJ, Mithani S, Dressman JB. Physiochemical and physiological mechanisms for the effects of food on drug absorption: the role of lipids and pH. J Pharm Sci. 1997; 86:269-282. [PubMed: 9050793]

Chan LN. Drug-nutrient interaction in clinical nutrition. Curr Opin Clin Nutr Metab Care. 2002; 5:327-332. [PubMed: 11953660]

Chang JL, Bigler J, Schwarz Y, Li SS, Li L, King IB, et al. UGT1A1 polymorphism is associated with serum bilirubin concentrations in a randomized, controlled, fruit and vegetable feeding trial. J Nutr. 2007; 137:890-897. [PubMed: 17374650]

Chen ST, Dou J, Temple R, Agarwal R, Wu KM, Walker S. New therapies from old medicines. Nat Biotechnol. 2008; 26:1077-1083. [PubMed: 18846070]

Chien JY, Friedrich S, Heathman MA, de Alwis DP, Sinha V. Pharmacokinetics/pharmacodynamics and the stages of drug development: role of modeling and simulation. AAPS J. 2005; 7:E544-559. [PubMed: 16353932]

Chow HH, Hakim IA, Vining DR, Crowell JA, Cordova CA, Chew WM, et al. Effects of repeated green tea catechin administration on human cytochrome P450 activity. Cancer Epidemiol Biomarkers Prev. 2006; 15:2473-2476. [PubMed: 17164372]

Chu X, Philip G, Evers R. Comments on Mougey et al. (2009): Absorption of montelukast is transporter mediated: a common variant of OATP2B1 is associated with reduced plasma concentrations and poor response. Pharmacogenet Genomics 19: 129-138. Pharmacogenet Genomics. 2012; 22:319-322. [PubMed: 22173088]

Chun AH, Erdman K, Chiu YL, Pilmer BL, Achari R, Cavanaugh JH. Bioavailability of lansoprazole granules administered in juice or soft food compared with the intact capsule formulation. Clin Ther. 2002; 24:1322-1331. [PubMed: 12240782]

Clarke TA, Waskell LA. The metabolism of clopidogrel is catalyzed by human cytochrome P450 $3 \mathrm{~A}$ and is inhibited by atorvastatin. Drug Metab Dispos. 2003; 31:53-59. [PubMed: 12485953]

Cohen, EEW.; Hartford, C.; Maitland, ML.; Fox-Kay, K.; Vogel, P.; Wu, K.; Ratain, MJ. Grapefruit juice significantly increases bioavailability of weekly rapamycin (sirolimus)-evidence of safety and activity in a phase 1 study. American Association for Cancer Research 100th Annual Meeting Abstract LB-135; Denver, CO. April 18-22 2009; American Association for Cancer Research; 2009.

Colalto C. Herbal interactions on absorption of drugs: Mechanisms of action and clinical risk assessment. Pharmacol Res. 2010; 62:207-227. [PubMed: 20399862]

Coughtrie MW, Johnston LE. Interactions between dietary chemicals and human sulfotransferasesmolecular mechanisms and clinical significance. Drug Metab Dispos. 2001; 29:522-528. [PubMed: 11259344]

Custodio JM, Wu CY, Benet LZ. Predicting drug disposition, absorption/elimination/transporter interplay and the role of food on drug absorption. Adv Drug Deliv Rev. 2008; 60:717-733. [PubMed: 18199522]

Cvetkovic M, Leake B, Fromm MF, Wilkinson GR, Kim RB. OATP and P-glycoprotein transporters mediate the cellular uptake and excretion of fexofenadine. Drug Metab Dispos. 1999; 27:866-871. [PubMed: 10421612]

De Castro WV, Mertens-Talcott S, Rubner A, Butterweck V, Derendorf H. Variation of flavonoids and furanocoumarins in grapefruit juices: a potential source of variability in grapefruit juice-drug interaction studies. J Agric Food Chem. 2006; 54:249-255. [PubMed: 16390207]

Dentali SJ. Successful botanical research requires botanical expertise. Clin Pharmacol Ther. 2010; 87:149-151. [PubMed: 20107447] 
Derendorf, H.; Hochhaus, G. Handbook of pharmacokinetic pharmacodynamic correlations (pharmacology and toxicology). Florida: CRC Press; 1995.

Donovan JL, Chavin KD, Devane CL, Taylor RM, Wang JS, Ruan Y, et al. Green tea (Camellia sinensis) extract does not alter cytochrome p450 3A4 or 2D6 activity in healthy volunteers. Drug Metab Dispos. 2004; 32:906-908. [PubMed: 15319329]

Dresser GK, Kim RB, Bailey DG. Effect of grapefruit juice volume on the reduction of fexofenadine bioavailability: possible role of organic anion transporting polypeptides. Clin Pharmacol Ther. 2005; 77:170-177. [PubMed: 15735611]

Dreosti IE. Bioactive ingredients: antioxidants and polyphenols in tea. Nutr Rev. 1996; 54:S51-8. [PubMed: 9110576]

Eagle K. Toxicological effects of red wine, orange juice, and other dietary SULT1A inhibitors via excess catecholamines. Food Chem Toxicol. 201210.1016/j.fct.2012.03.004

Edwards DJ, Fitzsimmons ME, Schuetz EG, Yasuda K, Ducharme MP, Warbasse LH, et al. 6' , $7^{\prime}$ Dihydroxybergamottin in grapefruit juice and Seville orange juice: effects on cyclosporine disposition, enterocyte CYP3A4, and P-glycoprotein. Clin Pharmacol Ther. 1999; 65:237-244. [PubMed: 10096255]

Einolf HJ. Comparison of different approaches to predict metabolic drug-drug interactions. Xenobiotica. 2007; 37:1257-1294. [PubMed: 17968745]

Espin JC, Garcia-Conesa MT, Tomas-Barberan FA. Nutraceuticals: facts and fiction. Phytochemistry. 2007; 68:2986-3008. [PubMed: 17976666]

Fahmi OA, Maurer TS, Kish M, Cardenas E, Boldt S, Nettleton D. A combined model for predicting CYP3A4 clinical net drug-drug interaction based on CYP3A4 inhibition, inactivation, and induction determined in vitro. Drug Metab Dispos. 2008; 36:1698-1708. [PubMed: 18490437]

Fahmi OA, Hurst S, Plowchalk D, Cook J, Guo F, Youdim K, et al. Comparison of different algorithms for predicting clinical drug-drug interactions, based on the use of CYP3A4 in vitro data: predictions of compounds as precipitants of interaction. Drug Metab Dispos. 2009; 37:16581666. [PubMed: 19406954]

Fan J, Chen S, Chow EC, Pang KS. PBPK modeling of intestinal and liver enzymes and transporters in drug absorption and sequential metabolism. Curr Drug Metab. 2010; 11:743-761. [PubMed: 21189137]

Farkas D, Greenblatt DJ. Influence of fruit juices on drug disposition: discrepancies between in vitro and clinical studies. Expert Opin Drug Metab Toxicol. 2008; 4:381-393. [PubMed: 18433343]

Farkas D, Oleson LE, Zhao Y, Harmatz JS, Zinny MA, Court MH, et al. Pomegranate juice does not impair clearance of oral or intravenous midazolam, a probe for cytochrome P450-3A activity: comparison with grapefruit juice. J Clin Pharmacol. 2007; 47:286-294. [PubMed: 17322140]

Fenneteau F, Poulin P, Nekka F. Physiologically based predictions of the impact of inhibition of intestinal and hepatic metabolism on human pharmacokinetics of CYP3A substrates. J Pharm Sci. 2010; 99:486-514. [PubMed: 19479982]

Fisher MB, Paine MF, Strelevitz TJ, Wrighton SA. The role of hepatic and extrahepatic UDPglucuronosyltransferases in human drug metabolism. Drug Metab Rev. 2001; 33:273-297. [PubMed: 11768770]

Fleisher D, Li C, Zhou Y, Pao LH, Karim A. Drug, meal and formulation interactions influencing drug absorption after oral administration. Clinical implications. Clin Pharmacokinet. 1999; 36:233-254. [PubMed: 10223170]

Foster BC, Kearns N, Arnason JT, Saleem A, Ogrodowczyk C, Desjardins S. Comparative study of hop-containing products on human cytochrome p450-mediated metabolism. J Agric Food Chem. 2009; 57:5100-5105. [PubMed: 19489632]

Foster BC, Arnason JT, Saleem A, Tam TW, Liu R, Mao J, et al. Comparative study of hopscontaining products on human cytochrome P450-mediated metabolism. J Agric Food Chem. 2011; 59:5159-5163. [PubMed: 21476568]

Fuchikami H, Satoh H, Tsujimoto M, Ohdo S, Ohtani H, Sawada Y. Effects of herbal extracts on the function of human organic anion-transporting polypeptide OATP-B. Drug Metab Dispos. 2006; 34:577-582. [PubMed: 16415120] 
Fukazawa I, Uchida N, Uchida E, Yasuhara H. Effects of grapefruit juice on pharmacokinetics of atorvastatin and pravastatin in Japanese. Br J Clin Pharmacol. 2004; 57:448-455. [PubMed: 15025743]

Galetin A, Ito K, Hallifax D, Houston JB. CYP3A4 substrate selection and substitution in the prediction of potential drug-drug interactions. J Pharmacol Exp Ther. 2005; 314:180-190. [PubMed: 15784650]

Galetin A, Burt H, Gibbons L, Houston JB. Prediction of time-dependent CYP3A4 drug-drug interactions: impact of enzyme degradation, parallel elimination pathways, and intestinal inhibition. Drug Metab Dispos. 2006; 34:166-175. [PubMed: 16221752]

Galetin A, Hinton LK, Burt H, Obach RS, Houston JB. Maximal inhibition of intestinal first-pass metabolism as a pragmatic indicator of intestinal contribution to the drug-drug interactions for CYP3A4 cleared drugs. Curr Drug Metab. 2007; 8:685-693. [PubMed: 17979656]

Galetin A, Gertz M, Houston JB. Potential role of intestinal first-pass metabolism in the prediction of drug-drug interactions. Expert Opin Drug Metab Toxicol. 2008; 4:909-922. [PubMed: 18624679]

Galetin A, Gertz M, Houston JB. Contribution of intestinal cytochrome P450-mediated metabolism to drug-drug inhibition and induction interactions. Drug Metab Pharmacokinet. 2010; 25:28-47. [PubMed: 20208387]

Gamage N, Barnett A, Hempel N, Duggleby RG, Windmill KF, Martin JL, et al. Human sulfotransferases and their role in chemical metabolism. Toxicol Sci. 2006; 90:5-22. [PubMed: 16322073]

Genser D. Food and drug interaction: consequences for the nutrition/health status. Ann Nutr Metab. 2008; 52(Suppl 1):29-32. [PubMed: 18382075]

Gerhauser C. Cancer chemopreventive potential of apples, apple juice, and apple components. Planta Med. 2008; 74:1608-1624. [PubMed: 18855307]

Gertz M, Harrison A, Houston JB, Galetin A. Prediction of human intestinal first-pass metabolism of 25 CYP3A substrates from in vitro clearance and permeability data. Drug Metab Dispos. 2010; 38:1147-1158. [PubMed: 20368326]

Gertz M, Houston JB, Galetin A. Physiologically based pharmacokinetic modeling of intestinal firstpass metabolism of CYP3A substrates with high intestinal extraction. Drug Metab Dispos. 2011; 39:1633-1642. [PubMed: 21632965]

Gibbs MA, Hosea NA. Factors affecting the clinical development of cytochrome p450 CYP3A substrates. Clin Pharmacokinet. 2003; 42:969-984. [PubMed: 12908853]

Glaeser H, Bailey DG, Dresser GK, Gregor JC, Schwarz UI, McGrath JS, et al. Intestinal drug transporter expression and the impact of grapefruit juice in humans. Clin Pharmacol Ther. 2007; 81:362-370. [PubMed: 17215845]

Glisson JK, Walker LA. How physicians should evaluate dietary supplements. Am J Med. 2010; 123:577-582. [PubMed: 20493463]

Gobburu JV, Marroum PJ. Utilisation of pharmacokinetic-pharmacodynamic modelling and simulation in regulatory decision-making. Clin Pharmacokinet. 2001; 40:883-892. [PubMed: 11735607]

Gruenwald J. Novel botanical ingredients for beverages. Clin Dermatol. 2009; 27:210-216. [PubMed: 19168002]

Guest EJ, Rowland-Yeo K, Rostami-Hodjegan A, Tucker GT, Houston JB, Galetin A. Assessment of algorithms for predicting drug-drug interactions via inhibition mechanisms: comparison of dynamic and static models. Br J Clin Pharmacol. 2011; 71:72-87. [PubMed: 21143503]

Guilford JM, Pezzuto JM. Wine and health: a review. Am J Enol Vitic. 2011; 62:471-486.

Guinda A, Rada M, Delgado T, Gutiérrez-Adánez P, Castellano JM. Pentacyclic triterpenoids from olive fruit and leaf. J Agric Food Chem. 2010; 58:9685-9691. [PubMed: 20712364]

Guo LQ, Fukuda K, Ohta T, Yamazoe Y. Role of furanocoumarin derivatives on grapefruit juicemediated inhibition of human CYP3A activity. Drug Metab Dispos. 2000; 28:766-771. [PubMed: 10859150]

Gurley BJ. Clinical pharmacology and dietary supplements: an evolving relationship. Clin Pharmacol Ther. 2010; 87:235-238. [PubMed: 19940848]

Hagenbuch B, Gui C. Xenobiotic transporters of the human organic anion transporting polypeptides (OATP) family. Xenobiotica. 2008; 38:778-801. [PubMed: 18668430] 
Hanley MJ, Cancalon P, Widmer WW, Greenblatt DJ. The effect of grapefruit juice on drug disposition. Expert Opin Drug Metab Toxicol. 2011; 7:267-286. [PubMed: 21254874]

Harbourt DE, Fallon JK, Ito S, Baba T, Ritter JK, Glish GL, et al. Quantification of human uridinediphosphate glucuronosyl transferase 1A isoforms in liver, intestine, and kidney using nanobore liquid chromatography-tandem mass spectrometry. Anal Chem. 2012; 84:98-105. [PubMed: 22050083]

Harris RM, Waring RH. Sulfotransferase inhibition: potential impact of diet and environmental chemicals on steroid metabolism and drug detoxification. Curr Drug Metab. 2008; 9:269-275. [PubMed: 18473744]

He X, Liu RH. Cranberry phytochemicals: Isolation, structure elucidation, and their antiproliferative and antioxidant activities. J Agric Food Chem. 2006; 54:7069-7074. [PubMed: 16968064]

Henderson MC, Miranda CL, Stevens JF, Deinzer ML, Buhler DR. In vitro inhibition of human P450 enzymes by prenylated fl avonoids from hops, Humulus lupulus. Xenobiotica. 2000; 30:235-251. [PubMed: 10752639]

Hidaka M, Okumura M, Fujita K, Ogikubo T, Yamasaki K, Iwakiri T, et al. Effects of pomegranate juice on human cytochrome p450 3A (CYP3A) and carbamazepine pharmacokinetics in rats. Drug Metab Dispos. 2005; 33:644-648. [PubMed: 15673597]

Hisaka A, Ohno Y, Yamamoto T, Suzuki H. Theoretical considerations on quantitative prediction of drug-drug interactions. Drug Metab Pharmacokinet. 2010; 25:48-61. [PubMed: 20208388]

Ho PC, Saville DJ, Coville PF, Wanwimolruk S. Content of CYP3A4 inhibitors, naringin, naringenin and bergapten in grapefruit and grapefruit juice products. Pharm Acta Helv. 2000; 74:379-385. [PubMed: 10812937]

Holbrook AM, Pereira JA, Labiris R, McDonald H, Douketis JD, Crowther M, et al. Systematic overview of warfarin and its drug and food interactions. Arch Intern Med. 2005; 165:1095-1106. [PubMed: 15911722]

Holford N, Ma SC, Ploeger BA. Clinical trial simulation: a review. Clin Pharmacol Ther. 2010; 88:166-182. [PubMed: 20613720]

Houston JB, Galetin A. Methods for predicting in vivo pharmacokinetics using data from in vitro assays. Curr Drug Metab. 2008; 9:940-951. [PubMed: 18991591]

Huang SM, Strong JM, Zhang L, Reynolds KS, Nallani S, Temple R, et al. New era in drug interaction evaluation: US Food and Drug Administration update on CYP enzymes, transporters, and the guidance process. J Clin Pharmacol. 2008; 48:662-670. [PubMed: 18378963]

Huang SM, Zhao H, Lee JI, Reynolds K, Zhang L, Temple R, et al. Therapeutic protein-drug interactions and implications for drug development. Clin Pharmacol Ther. 2010; 87:497-503. [PubMed: 20200513]

Huvaere K, Andersen ML, Olsen K, Skibsted LH, Heyerick A, De Keukeleire D. Radicaloid-type oxidative decomposition of beer bittering agents revealed. Chemistry. 2003; 9:4693-4699. [PubMed: 14566875]

Ieiri I, Doi Y, Maeda K, Sasaki T, Kimura M, Hirota T, et al. Microdosing clinical study: pharmacokinetic, pharmacogenomic (SLCO2B1), and interaction (grapefruit juice) profiles of celiprolol following the oral microdose and therapeutic dose. J Clin Pharmacol. 201110.1177/0091270011408612

Imanaga J, Kotegawa T, Imai H, Tsutsumi K, Yoshizato T, Ohyama T, et al. The effects of the SLCO2B1 c.1457C $>\mathrm{T}$ polymorphism and apple juice on the pharmacokinetics of fexofenadine and midazolam in humans. Pharmacogenet Genomics. 2011; 21:84-93. [PubMed: 21280267]

Jang GR, Harris RZ. Drug interactions involving ethanol and alcoholic beverages. Expert Opin Drug Metab Toxicol. 2007; 3:719-731. [PubMed: 17916057]

Jeon, H.; Lim, KS.; Ohashi, K.; Kotegawa, T.; Ieiri, I.; Cho, JY.; Yoon, SH.; Shin, SG.; Yu, KS.; Jang, IJ. Apple juice greatly reduces plasma concentrations of atenolol. 2012 American Society for Clinical Pharmacology and Therapeutics Annual Meeting Abstract PII-78; National Harbor, MD. March 12-17, 2012; American Society for Clinical Pharmacology and Therapeutics; 2012.

Jung H, Peregrina AA, Rodriquez JM, Moreno-Esparza R. The influence of coffee with milk and tea with milk on the bioavailability of tetracycline. Biopharm Drug Dispos. 1997; 18:459-463. [PubMed: 9210983] 
Kakar SM, Paine MF, Stewart PW, Watkins PB. $6^{\prime} 7^{\prime}$-Dihydroxybergamottin contributes to the grapefruit juice effect. Clin Pharmacol Ther. 2004; 75:569-579. [PubMed: 15179411]

Kaplan NM, Palmer BF. Nutritional and health benefits of beer. Am J Med Sci. 2000; 320:320-326. [PubMed: 11093684]

Kato Y, Miyazaki T, Kano T, Sugiura T, Kubo Y, Tsuji A. Involvement of influx and efflux transport systems in gastrointestinal absorption of celiprolol. J Pharm Sci. 2009; 98:2529-2539. [PubMed: 19067419]

Kazui M, Nishiya Y, Ishizuka T, Hagihara K, Farid NA, Okazaki O, et al. Identification of the human cytochrome $\mathrm{P} 450$ enzymes involved in the two oxidative steps in the bioactivation of clopidogrel to its pharmacologically active metabolite. Drug Metab Dispos. 2010; 38:92-99. [PubMed: 19812348]

Kim E, Sy-Cordero A, Graf TN, Brantley SJ, Paine MF, Oberlies NH. Isolation and identification of intestinal CYP3A inhibitors from cranberry (Vaccinium macrocarpon) using human intestinal microsomes. Planta Med. 2011; 77:265-270. [PubMed: 20717876]

Kim H, Yoon YJ, Shon JH, Cha IJ, Shin JG, Liu KH. Inhibitory effects of fruit juices on CYP3A activity. Drug Metab Dispos. 2006; 34:521-523. [PubMed: 16415112]

Kim RB. Organic anion-transporting polypeptide (OATP) transporter family and drug disposition. Eur J Clin Invest. 2003; 33(Suppl 2):1-5. [PubMed: 14641549]

Kimura S, Kako S, Wada H, Sakamoto K, Ashizawa M, Sato M, et al. Can grapefruit juice decrease the cost of imatinib for the treatment of chronic myelogenous leukemia? Leuk Res. 2011; 35:e11-12. [PubMed: 20952061]

Klaassen CD, Boles JW. Sulfation and sulfotransferases 5: the importance of $3^{\prime}$-phosphoadenosine $5^{\prime}$ phosphosulfate (PAPS) in the regulation of sulfation. FASEB J. 1997; 11:404-418. [PubMed: 9194521]

Krenz M, Korthuis RJ. Moderate ethanol ingestion and cardiovascular protection: from epidemiologic associations to cellular mechanisms. J Mol Cell Cardiol. 2012; 52:93-104. [PubMed: 22041278]

Kupferschmidt HH, Ha HR, Ziegler WH, Meier PJ, Krahenbuhl S. Interaction between grapefruit juice and midazolam in humans. Clin Pharmacol Ther. 1995; 58:20-28. [PubMed: 7628179]

Laverdière I, Caron P, Harvey M, Lévesque É, Guillemette C. In vitro investigation of human UDPglucuronosyltransferase isoforms responsible for tacrolimus glucuronidation: predominant contribution of UGT1A4. Drug Metab Dispos. 2011; 39:1127-1130. [PubMed: 21487055]

Lentz KA. Current methods for predicting human food effect. AAPS J. 2008; 10:282-288. [PubMed: 18500565]

Le Tiec C, Barrail A, Goujard C, Taburet AM. Clinical pharmacokinetics and summary of efficacy and tolerability of atazanavir. Clin Pharmacokinet. 2005; 44:1035-1050. [PubMed: 16176117]

Li Z, Vachharajani NN, Krishna R. On the assessment of effects of food on the pharmacokinetics of drugs in early development. Biopharm Drug Dispos. 2002; 23:165-71. [PubMed: 12015791]

Liederer BM, Borchardt RT. Enzymes involved in the bioconversion of ester-based prodrugs. J Pharm Sci. 2006; 95:1177-1195. [PubMed: 16639719]

Lilja JJ, Kivistö KT, Neuvonen PJ. Grapefruit juice increases serum concentrations of atorvastatin and has no effect on pravastatin. Clin Pharmacol Ther. 1999; 66:118-127. [PubMed: 10460065]

Lilja JJ, Kivistö KT, Backman JT, Neuvonen PJ. Effect of grapefruit juice dose on grapefruit juicetriazolam interaction: repeated consumption prolongs triazolam half-life. Eur J Clin Pharmacol. 2000; 56:411-415. [PubMed: 11009051]

Lilja JJ, Backman JT, Laitila J, Luurila H, Neuvonen PJ. Itraconazole increases but grapefruit juice greatly decreases plasma concentrations of celiprolol. Clin Pharmacol Ther. 2003; 73:192-198. [PubMed: 12621384]

Lilja JJ, Juntti-Patinen L, Neuvonen PJ. Orange juice substantially reduces the bioavailability of the beta-adrenergic-blocking agent celiprolol. Clin Pharmacol Ther. 2004; 75:184-190. [PubMed: 15001969]

Lilja JJ, Neuvonen M, Neuvonen PJ. Effects of regular consumption of grapefruit juice on the pharmacokinetics of simvastatin. Br J Clin Pharmacol. 2004; 58:56-60. [PubMed: 15206993]

Lilja JJ, Raaska K, Neuvonen PJ. Effects of orange juice on the pharmacokinetics of atenolol. Eur J Clin Pharmacol. 2005; 61:337-340. [PubMed: 15983823] 
Lilja JJ, Backman JT, Neuvonen PJ. Effects of daily ingestion of cranberry juice on the pharmacokinetics of warfarin, tizanidine, and midazolam-probes of CYP2C9, CYP1A2, and CYP3A4. Clin Pharmacol Ther. 2007; 81:833-839. [PubMed: 17392729]

Lin JH, Lu AY. Interindividual variability in inhibition and induction of cytochrome P450 enzymes. Annu Rev Pharmacol Toxicol. 2001; 41:535-567. [PubMed: 11264468]

Liu C, Shang YF, Zhang XF, Zhang XG, Wang B, Wu Z, et al. Co-administration of grapefruit juice increases bioavailability of tacrolimus in liver transplant patients: a prospective study. Eur J Clin Pharmacol. 2009; 65:881-885. [PubMed: 19629461]

Lourenço R. Enteral feeding: drug/nutrient interaction. Clin Nutr. 2001; 20:187-193. [PubMed: 11327750]

Lown KS, Bailey DG, Fontana RJ, Janardan SK, Adair CH, Fortlage LA, et al. Grapefruit juice increases felodipine oral availability in humans by decreasing intestinal CYP3A protein expression. J Clin Invest. 1997; 99:2545-2553. [PubMed: 9153299]

Maeda T, Takahashi K, Ohtsu N, Oguma T, Ohnishi T, Atsumi R, et al. Identification of influx transporter for the quinolone antibacterial agent levofloxacin. Mol Pharm. 2007; 4:85-94. [PubMed: 17274666]

Malhotra S, Bailey DG, Paine MF, Watkins PB. Seville orange juice-felodipine interaction: comparison with dilute grapefruit juice and involvement of furocoumarins. Clin Pharmacol Ther. 2001; 69:14-23. [PubMed: 11180034]

Mandery K, Bujok K, Schmidt I, Keiser M, Siegmund W, Balk B, et al. Influence of the flavonoids apigenin, kaempferol, and quercetin on the function of organic anion transporting polypeptides 1A2 and 2B1. Biochem Pharmacol. 2010; 80:1746-1753. [PubMed: 20797388]

Markowitz JS, von Moltke LL, Donovan JL. Predicting interactions between conventional medications and botanical products on the basis of in vitro investigations. Mol Nutr Food Res. 2008; 52:747754. [PubMed: 18324706]

McCabe BJ. Prevention of food-drug interactions with special emphasis on older adults. Curr Opin Clin Nutr Metab Care. 2004; 7:21-26. [PubMed: 15090899]

McCabe, BJ.; Frankel, EH.; Wolfe, JJ. Handbook of food-drug interactions. Florida: CRC Press; 2003.

Meckling, KA. Nutrient-drug interactions. Florida: CRC Press; 2007.

Meech R, Mackenzie PI. Structure and function of uridine diphosphate glucuronosyltransferases. Clin Exp Pharmacol Physiol. 1997; 24:907-915. [PubMed: 9406655]

Mertens-Talcott SU, Zadezensky I, De Castro WV, Derendorf H, Butterweck V. Grapefruit-drug interactions: can interactions with drugs be avoided? J Clin Pharmacol. 2006; 46:1390-1416. [PubMed: 17101740]

Methlie P, Husebye EE, Hustad S, Lien EA, Løvås K. Grapefruit juice and licorice increase cortisol availability in patients with Addison's disease. Eur J Endocrinol. 2011; 165:761-769. [PubMed: 21896619]

Miles AA, Maskell JP. The neutralization of antibiotic action by metallic cations and iron chelators. J Antimicrob Chemother. 1986; 17:481-487. [PubMed: 3519562]

Miller R, Ewy W, Corrigan BW, Ouellet D, Hermann D, Kowalski KG, et al. How modeling and simulation have enhanced decision making in new drug development. J Pharmacokinet Pharmacodyn. 2005; 32:185-197. [PubMed: 16283534]

Ming X, Knight BM, Thakker DR. Vectorial transport of fexofenadine across Caco-2 cells: involvement of apical uptake and basolateral efflux transporters. Mol Pharm. 2011; 8:1677-1686. [PubMed: 21780830]

Misaka S, Nakamura R, Uchida S, Takeuchi K, Takahashi N, Inui N, et al. Effect of 2 weeks' consumption of pomegranate juice on the pharmacokinetics of a single dose of midazolam: an open-label, randomized, single-center, 2-period crossover study in healthy Japanese volunteers. Clin Ther. 2011; 33:246-252. [PubMed: 21497708]

Mohamed ME, Frye RF. Inhibitory effects of commonly used herbal extracts on UDPglucuronosyltransferase 1A4, 1A6, and 1A9 enzyme activities. Drug Metab Dispos. 2011; 39:1522-1528. [PubMed: 21632963] 
Mougey EB, Feng H, Castro M, Irvin CG, Lima JJ. Absorption of montelukast is transporter mediated: a common variant of OATP2B1 is associated with reduced plasma concentrations and poor response. Pharmacogenet Genomics. 2009; 19:129-138. [PubMed: 19151602]

Mougey EB, Lang JE, Wen X, Lima JJ. Effect of citrus juice and SLCO2B1 genotype on the pharmacokinetics of montelukast. J Clin Pharmacol. 2011; 51:751-760. [PubMed: 20974993]

Mouly SJ, Matheny C, Paine MF, Smith G, Lamba J, Lamba V, et al. Variation in oral clearance of saquinavir is predicted by $C Y P 3 A 5^{*} 1$ genotype but not by enterocyte content of cytochrome P450 3A5. Clin Pharmacol Ther. 2005; 78:605-618. [PubMed: 16338276]

Navarro SL, Peterson S, Chen C, Makar KW, Schwarz Y, King IB, et al. Cruciferous vegetable feeding alters UGT1A1 activity: diet- and genotype-dependent changes in serum bilirubin in a controlled feeding trial. Cancer Prev Res (Phila). 2009; 2:345-52. [PubMed: 19336732]

Navarro SL, Chen Y, Li L, Li SS, Chang JL, Schwarz Y, et al. UGT1A6 and UGT2B15 polymorphisms and acetaminophen conjugation in response to a randomized, controlled diet of select fruits and vegetables. Drug Metab Dispos. 2011; 39:1650-1657. [PubMed: 21666065]

Neuhofel AL, Wilton JH, Victory JM, Hejmanowsk LG, Amsden GW. Lack of bioequivalence of ciprofloxacin when administered with calcium-fortified orange juice: a new twist on an old interaction. J Clin Pharmacol. 2002; 42:461-466. [PubMed: 11936572]

Ngo N, Yan Z, Graf TN, Carrizosa DR, Kashuba AD, Dees EC, et al. Identification of a cranberry juice product that inhibits enteric CYP3A-mediated first-pass metabolism in humans. Drug Metab Dispos. 2009; 37:514-522. [PubMed: 19114462]

Nishimuta H, Tsujimoto M, Ogura K, Hiratsuka A, Ohtani H, Sawada Y. Inhibitory effects of various beverages on ritodrine sulfation by recombinant human sulfotransferase isoforms SULT1A1 and SULT1A3. Pharm Res. 2005; 22:1406-1410. [PubMed: 16078151]

Nishimuta H, Ohtani H, Tsujimoto M, Ogura K, Hiratsuka A, Sawada Y. Inhibitory effects of various beverages on human recombinant sulfotransferase isoforms SULT1A1 and SULT1A3. Biopharm Drug Dispos. 2007; 28:491-500. [PubMed: 17876860]

Obach RS, Walsky RL, Venkatakrishnan K, Houston JB, Tremaine LM. In vitro cytochrome P450 inhibition data and the prediction of drug-drug interactions: qualitative relationships, quantitative predictions, and the rank-order approach. Clin Pharmacol Ther. 2005; 78:582-592. [PubMed: 16338274]

Obach RS, Walsky RL, Venkatakrishnan K, Gaman EA, Houston JB, Tremaine LM. The utility of in vitro cytochrome $\mathrm{P} 450$ inhibition data in the prediction of drug-drug interactions. J Pharmacol Exp Ther. 2006; 316:336-348. [PubMed: 16192315]

Obach RS, Walsky RL, Venkatakrishnan K. Mechanism-based inactivation of human cytochrome p450 enzymes and the prediction of drug-drug interactions. Drug Metab Dispos. 2007; 35:246255. [PubMed: 17093004]

Obach RS. Predicting drug-drug interactions from in vitro drug metabolism data: challenges and recent advances. Curr Opin Drug Discov Devel. 2009; 12:81-89.

Paine MF, Criss AB, Watkins PB. Two major grapefruit juice components differ in intestinal CYP3A4 inhibition kinetic and binding properties. Drug Metab Dispos. 2004; 32:1146-1153. [PubMed: 15269184]

Paine MF, Criss AB, Watkins PB. Two major grapefruit juice components differ in time to onset of intestinal CYP3A4 inhibition. J Pharmacol Exp Ther. 2005; 312:1151-1160. [PubMed: 15485894]

Paine MF, Hart HL, Ludington SS, Haining RL, Rettie AE, Zeldin DC. The human intestinal cytochrome P450 “pie”. Drug Metab Dispos. 2006; 34:880-886. [PubMed: 16467132]

Paine MF, Oberlies NH. Clinical relevance of the small intestine as an organ of drug elimination: drugfruit juice interactions. Expert Opin Drug Metab Toxicol. 2007; 3:67-80. [PubMed: 17269895]

Pang KS, Durk MR. Physiologically-based pharmacokinetic modeling for absorption, transport, metabolism and excretion. J Pharmacokinet Pharmacodyn. 2010; 37:591-615. [PubMed: 21153869]

Parrott N, Lukacova V, Fraczkiewicz G, Bolger MB. Predicting pharmacokinetics of drugs using physiologically based modeling-application to food effects. AAPS J. 2009; 11:45-53. [PubMed: 19184451] 
Parving HH, Brenner BM, McMurray JJ, de Zeeuw D, Haffner SM, Solomon SD, et al. Aliskiren trial in type 2 diabetes using cardio-renal endpoints (ALTITUDE): rationale and study design. Nephrol Dial Transplant. 2009; 24:1663-1671. [PubMed: 19145003]

Patchett AA. The chemistry of enalapril. Br J Clin Pharmacol. 1984; 18:201S-207S. [PubMed: 6085275]

Peltoniemi MA, Saari TI, Hagelberg NM, Laine K, Neuvonen PJ, Olkkola KT. $S$-ketamine concentrations are greatly increased by grapefruit juice. Eur J Clin Pharmacol. 201210.1007/ s00228-012-1214-9

Penzak SR, Acosta EP, Turner M, Edwards DJ, Hon YY, Desai HD, et al. Effect of Seville orange juice and grapefruit juice on indinavir pharmacokinetics. J Clin Pharmacol. 2002; 42:1165-1170. [PubMed: 12362932]

Peters SA. Identification of intestinal loss of a drug through physiologically based pharmacokinetic simulation of plasma concentration-time profiles. Clin Pharmacokinet. 2008; 47:245-259. [PubMed: 18336054]

Peterson S, Bigler J, Horner NK, Potter JD, Lampe JW. Cruciferae interact with the UGT1A1*28 polymorphism to determine serum bilirubin levels in humans. J Nutr. 2005; 135:1051-1055. [PubMed: 15867280]

Piver B, Berthou F, Dreano Y, Lucas D. Inhibition of CYP3A, CYP1A and CYP2E1 activities by resveratrol and other non volatile red wine components. Toxicol Lett. 2001; 125:83-91. [PubMed: 11701226]

Plosker GL, Scott LJ. Saquinavir: a review of its use in boosted regimens for treating HIV infection. Drugs. 2003; 63:1299-1324. [PubMed: 12790697]

Polk RE. Drug-drug interactions with ciprofloxacin and other fluoroquinolones. Am J Med. 1989; 87(5A):76S-81S. [PubMed: 2686430]

Poulin P, Jones RD, Jones HM, Gibson CR, Rowland M, Chien JY, et al. PHRMA CPCDC initiative on predictive models of human pharmacokinetics, part 5: Prediction of plasma concentrationtime profiles in human by using the physiologically-based pharmacokinetic modeling approach. J Pharm Sci. 201110.1002/jps. 22550

Pulido R, Hernández-García M, Saura-Calixto F. Contribution of beverages to the intake of lipophilic and hydrophilic antioxidants in the Spanish diet. Eur J Clin Nutr. 2003; 57:1275-1282. [PubMed: 14506489]

Qiao J, Gu C, Shang W, Du J, Yin W, Zhu M, et al. Effect of green tea on pharmacokinetics of 5fluorouracil in rats and pharmacodynamics in human cell lines in vitro. Food Chem Toxicol. 2011; 49:1410-1415. [PubMed: 21440026]

Radominska-Pandya A, Czernik PJ, Little JM, Battaglia E, Mackenzie PI. Structural and functional studies of UDP-glucuronosyltransferases. Drug Metab Rev. 1999; 31:817-899. [PubMed: 10575553]

Ravi PR, Vats R, Thakur R, Srivani S, Aditya N. Effect of grapefruit juice and ritonavir on pharmacokinetics of lopinavir in wistar rats. Phytother Res. 201210.1002/ptr.4593

Rebello S, Zhao S, Hariry S, Dahlke M, Alexander N, Vapurcuyan A, et al. Intestinal OATP1A2 inhibition as a potential mechanism for the effect of grapefruit juice on aliskiren pharmacokinetics in healthy subjects. Eur J Clin Pharmacol. 201110.1007/s00228-011-1167-4

Reddy P, Ellington D, Zhu Y, Zdrojewski I, Parent SJ, Harmatz JS, et al. Serum concentrations and clinical effects of atorvastatin in patients taking grapefruit juice daily. Br J Clin Pharmacol. 2011; 72:434-441. [PubMed: 21501216]

Ritter JK. Intestinal UGTs as potential modifiers of pharmacokinetics and biological responses to drugs and xenobiotics. Expert Opin Drug Metab Toxicol. 2007; 3:93-107. [PubMed: 17269897]

Rodríguez-Fragoso L, Martínez-Arismendi JL, Orozco-Bustos D, Reyes-Esparza J, Torres E, Burchiel SW. Potential risks resulting from fruit/vegetable-drug interactions: effects on drug-metabolizing enzymes and drug transporters. J Food Sci. 2011; 76:R112-R124. [PubMed: 22417366]

Ross SA, Ziska DS, Zhao K, ElSohly MA. Variance of common flavonoids by brand of grapefruit juice. Fitoterapia. 2000; 71:154-161. [PubMed: 10727812]

Roth M, Timmermann BN, Hagenbuch B. Interactions of green tea catechins with organic aniontransporting polypeptides. Drug Metab Dispos. 2011; 39:920-926. [PubMed: 21278283] 
Roth M, Araya JJ, Timmermann BN, Hagenbuch B. Isolation of modulators of the liver specific organic anion-transporting polypeptides (OATPs) 1B1 and 1B3 from Rollinia emarginata Schlecht (Annonaceae). J Pharmacol Exp Ther. 2011; 339:624-632. [PubMed: 21846839]

Rowland M, Peck C, Tucker G. Physiologically-based pharmacokinetics in drug development and regulatory science. Annu Rev Pharmacol Toxicol. 2011; 10:45-73. [PubMed: 20854171]

Sabra R. Topics in clinical pharmacology: lovastatin. Am J Med Sci. 1988; 296:426-428. [PubMed: 3063117]

Saito M, Hirata-Koizumi M, Matsumoto M, Urano T, Hasegawa R. Undesirable effects of citrus juice on the pharmacokinetics of drugs: focus on recent studies. Drug Saf. 2005; 28:677-694. [PubMed: 16048354]

Sang S, Lambert JD, Ho CT, Yang CS. The chemistry and biotransformation of tea constituents. Pharmacol Res. 2011; 64:87-99. [PubMed: 21371557]

Santos CA, Boullata JI. An approach to evaluating drug-nutrient interactions. Pharmacotherapy. 2005; 25:1789-1800. [PubMed: 16305298]

Saracino MR, Bigler J, Schwarz Y, Chang JL, Li S, Li L, et al. Citrus fruit intake is associated with lower serum bilirubin concentration among women with the UGT1A1*28 polymorphism. J Nutr. 2009; 139:555-560. [PubMed: 19141701]

Satoh H, Yamashita F, Tsujimoto M, Murakami H, Koyabu N, Ohtani H, et al. Citrus juices inhibit the function of human organic anion-transporting polypeptide OATP-B. Drug Metab Dispos. 33:518-523. [PubMed: 15640378]

Schmiedlin-Ren P, Edwards DJ, Fitzsimmons ME, He K, Lown KS, Woster PM, et al. Mechanisms of enhanced oral availability of CYP3A4 substrates by grapefruit constituents. Decreased enterocyte CYP3A4 concentration and mechanism-based inactivation by furanocoumarins. Drug Metab Dispos. 1997; 25:1228-1233. [PubMed: 9351897]

Seden K, Dickinson L, Khoo S, Back D. Grapefruit-drug interactions. Drugs. 2010; 70:2373-2407. [PubMed: 21142260]

Self TH, Chrisman CR, Baciewicz AM, Bronze MS. Isoniazid drug and food interactions. Am J Med Sci. 317:304-311. [PubMed: 10334118]

Shardlow CE, Generaux GT, MacLauchlin CC, Pons N, Skordos KW, Bloomer JC. Utilizing drugdrug interaction prediction tools during drug development: enhanced decision making based on clinical risk. Drug Metab Dispos. 2011; 39:2076-2084. [PubMed: 21832001]

Shen DD, Kunze KL, Thummel KE. Enzyme-catalyzed processes of first-pass hepatic and intestinal drug extraction. Adv Drug Deliv Rev. 1997; 27:99-127. [PubMed: 10837554]

Shoaf SE, Mallikaarjun S, Bricmont P. Effect of grapefruit juice on the pharmacokinetics of tolvaptan, a non-peptide arginine vasopressin antagonist, in healthy subjects. Eur J Clin Pharmacol. 68:207211. [PubMed: 21853290]

Singh BN. Effects of food on clinical pharmacokinetics. Clin Pharmacokinet. 1999; 37:213-255. [PubMed: 10511919]

Smillie TJ, Khan IA. A comprehensive approach to identifying and authenticating botanical products. Clin Pharmacol Ther. 2010; 87:175-186. [PubMed: 20032974]

Stargrove, MB.; Treasure, J.; McKee, DL. Herb, nutrient, and drug interactions: clinical implications and therapeutic strategies. Missouri: Mosby Elsevier; 2008.

Stupans L, Tan HW, Kirlich A, Tuck K, Hayball P, Murray M. Inhibition of CYP3A-mediated oxidation in human hepatic microsomes by the dietary derived complex phenol, gallic acid. $\mathrm{J}$ Pharm Pharmacol. 2002; 54:269-275. [PubMed: 11848291]

Sunaga K, Ohkawa K, Nakamura K, Ohkubo A, Harada S, Tsuda T. Mechanism-based inhibition of recombinant human cytochrome P450 3A4 by tomato juice extract. Biol Pharm Bull. 2012; 35:329-334. [PubMed: 22382318]

Tachibana T, Kato M, Takano J, Sugiyama Y. Predicting drug-drug interactions involving the inhibition of intestinal CYP3A4 and P-glycoprotein. Curr Drug Metab. 2010; 11:762-777. [PubMed: 21189139]

Tachibana T, Kato M, Sugiyama Y. Prediction of nonlinear intestinal absorption of CYP3A4 and Pglycoprotein substrates from their in vitro Km values. Pharm Res. 2012; 29:651-668. [PubMed: 21913031] 
Tapaninen T, Neuvonen PJ, Niemi M. Grapefruit juice greatly reduces the plasma concentrations of the OATP2B1 and CYP3A4 substrate aliskiren. Clin Pharmacol Ther. 2010; 88:339-342. [PubMed: 20664534]

Tapaninen T, Neuvonen PJ, Niemi M. Orange and apple juice greatly reduce the plasma concentrations of the OATP2B1 substrate aliskiren. Br J Clin Pharmacol. 2011; 71:718-726. [PubMed: 21204914]

Tateishi T, Soucek P, Caraco Y, Guengerich FP, Wood AJ. Colchicine biotransformation by human liver microsomes. Identification of CYP3A4 as the major isoform responsible for colchicine demethylation. Biochem Pharmacol. 1997; 53:111-116. [PubMed: 8960070]

Thummel KE, Wilkinson GR. In vitro and in vivo drug interactions involving human CYP3A. Annu Rev Pharmacol Toxicol. 1998; 38:389-430. [PubMed: 9597161]

Tidball CS. The nature of the intestinal epithelial barrier. Am J Dig Dis. 1971; 16:745-767. [PubMed: 4328906]

Tzulker R, Glazer I, Bar-Ilan I, Holland D, Aviram M, Amir R. Antioxidant activity, polyphenol content, and related compounds in different fruit juices and homogenates prepared from 29 different pomegranate accessions. J Agric Food Chem. 2007; 55:9559-9570. [PubMed: 17914875]

Uesawa Y, Mohri K. Effects of cranberry juice on nifedipine pharmacokinetics in rats. J Pharm Pharmacol. 2006; 58:1067-1072. [PubMed: 16872553]

Uesawa Y, Abe M, Fukuda E, Baba M, Okada Y, Mohri K. Construction of a model to estimate the CYP3A inhibitory effect of grapefruit juice. Pharmazie. 2011; 66:525-528. [PubMed: 21812328]

Valenzuela B, Rebollo J, Pérez T, Brugarolas A, Pérez-Ruixo JJ. Effect of grapefruit juice on the pharmacokinetics of docetaxel in cancer patients: a case report. Br J Clin Pharmacol. 2011; 72:978-981. [PubMed: 21692829]

van de Waterbeemd H, Gifford E. ADMET in silico modelling: towards prediction paradise? Nat Rev Drug Discov. 2003; 2:192-204. [PubMed: 12612645]

van der Logt EM, Roelofs HM, Nagengast FM, Peters WH. Induction of rat hepatic and intestinal UDP-glucuronosyltransferases by naturally occurring dietary anticarcinogens. Carcinogenesis. 2003; 24:1651-1656. [PubMed: 12869420]

Vinson JA, Mandarano M, Hirst M, Trevithick JR, Bose P. Phenol antioxidant quantity and quality in foods: beers and the effect of two types of beer on an animal model of atherosclerosis. J Agric Food Chem. 2003; 51:5528-5533. [PubMed: 12926909]

Vinson JA, Teufel K, Wu N. Green and black teas inhibit atherosclerosis by lipid, antioxidant, and fibrinolytic mechanisms. J Agric Food Chem. 2004; 52:3661-3665. [PubMed: 15161246]

Vischini G, Niscola P, Stefoni A, Farneti F. Increased plasma levels of tacrolimus after ingestion of green tea. Am J Kidney Dis. 2011; 58:329. [PubMed: 21787983]

Visioli F, De La Lastra CA, Andres-Lacueva C, Aviram M, Calhau C, Cassano A, et al. Polyphenols and human health: a prospectus. Crit Rev Food Sci Nutr. 2011; 51:524-546. [PubMed: 21929330]

Wallace AW, Victory JM, Amsden GW. Lack of bioequivalence when levofloxacin and calciumfortified orange juice are coadministered to healthy volunteers. J Clin Pharmacol. 2003; 43:539_ 544. [PubMed: 12751275]

Wanwimolruk S, Marquez PV. Variations in content of active ingredients causing drug interactions in grapefruit juice products sold in California. Drug Metabol Drug Interact. 2006; 21:233-243. [PubMed: 16841515]

Wason, S.; DiGiacinto, J.; Davis, MW. Consumption of grapefruit or Seville orange juice does not affect the pharmacokinetics of colchicine. American Society for Clinical Pharmacology and Therapeutics Annual Meeting Abstract PI-77; Dallas, TX. March 2-5, 2011; American Society for Clinical Pharmacology and Therapeutics; 2011.

Wolinsky, I.; Williams, L. Nutrition in pharmacy practice. Washington, DC: American Pharmaceutical Association; 2002.

Won CS, Oberlies NH, Paine MF. Influence of dietary substances on intestinal drug metabolism and transport. Curr Drug Metab. 11:778-792. [PubMed: 21189136] 
Wu CP, Ohnuma S, Ambudkar SV. Discovering natural product modulators to overcome multidrug resistance in cancer chemotherapy. Curr Pharm Biotechnol. 2011; 12:609-620. [PubMed: 21118092]

Yang J, Jamei M, Yeo KR, Tucker GT, Rostami-Hodjegan A. Prediction of intestinal first-pass drug metabolism. Curr Drug Metab. 2007; 8:676-684. [PubMed: 17979655]

Youdim KA, Zayed A, Dickins M, Phipps A, Griffiths M, Darekar A, et al. Application of CYP3A4 in vitro data to predict clinical drug-drug interactions; predictions of compounds as objects of interaction. Br J Clin Pharmacol. 2008; 65:680-692. [PubMed: 18279465]

Zaveri NT. Green tea and its polyphenolic catechins: medicinal uses in cancer and noncancer applications. Life Sci. 2006; 78:2073-2080. [PubMed: 16445946]

Zhao P, Zhang L, Grillo JA, Liu Q, Bullock JM, Moon YJ, et al. Applications of physiologically based pharmacokinetic (PBPK) modeling and simulation during regulatory review. Clin Pharmacol Ther. 2011; 89:259-267. [PubMed: 21191381] 


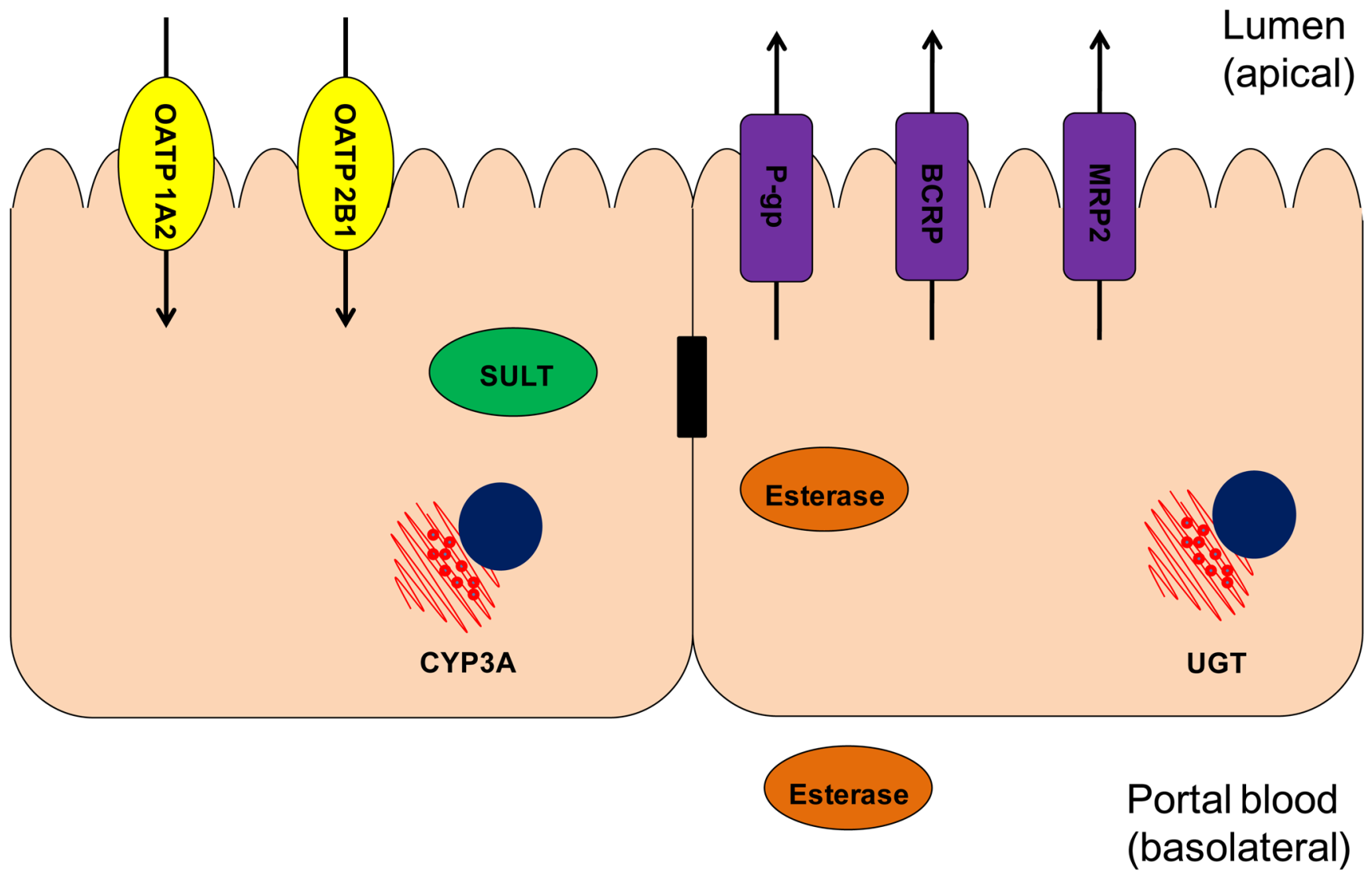

Fig. 1.

Schematic representation of enterocytes. Like drugs, dietary substances can alter systemic "victim" drug exposure by inhibiting enteric transporter-mediated uptake and/or efflux, as well as phase I and II metabolism. BCRP: breast cancer resistance protein, CYP: cytochrome P450, MRP: multidrug resistance-associated protein, OATP: organic aniontransporting polypeptide, P-gp: P-glycoprotein, SULT: sulfotransferase, UGT: UDPglucuronosyltransferase. 
Table 1

Summary of recent ${ }^{*}$ controlled clinical studies involving CYP3A-mediated citrus juice-drug interactions

\begin{tabular}{|c|c|c|c|c|}
\hline Citrus Juice & Subjects (n) & $\begin{array}{l}\text { Administration Regimen of Drug and Juice } \\
\text { Product (Manufacturer) }\end{array}$ & $\begin{array}{l}\text { Change in Mean } \\
\text { AUC }\end{array}$ & Reference \\
\hline \multirow[t]{8}{*}{ Grapefruit } & Healthy volunteers (12) & $\begin{array}{l}S \text {-ketamine } 0.2 \mathrm{mg} / \mathrm{kg} \times 1 \text { on Day } 5 \\
\text { Normal strength (Greippi Täysmehu; Valio Ltd., } \\
\text { Helsinki, Finland) } \\
\text { Pre-treament: } 200 \mathrm{~mL} \text { tid } \times 4 \text { days } \\
\text { Day 5: } 150 \mathrm{~mL} \text { with } S \text {-ketamine, } 200 \mathrm{~mL} \times 2 \text { per } \\
\text { pre-treatment schedule }\end{array}$ & $\uparrow 185 \%{ }^{\dagger}(\mathrm{p}<0.001)$ & $\begin{array}{l}\text { Peltoniemi et } \\
\text { al., } 2012\end{array}$ \\
\hline & $\begin{array}{l}\text { Addison's disease patients } \\
\text { (17) }\end{array}$ & $\begin{array}{l}\text { Cortisone acetate }{ }^{\#} 6.3 \text { to } 25 \mathrm{mg} \text { bid or tid per } \\
\text { patient's prescribed regimen }\end{array}$ & $\begin{array}{l}\text { Cortisol: } \uparrow 19 \%{ }^{\dagger}(\mathrm{p}< \\
0.05)\end{array}$ & $\begin{array}{l}\text { Methlie et al., } \\
2011\end{array}$ \\
\hline & & $\begin{array}{l}\text { Normal strength (Meierienes Premium Rosa } \\
\text { Grapefruktjuice; Tine SA, Oslo, Norway) } \\
200 \mathrm{~mL} \text { tid with cortisone acetate } \times 2 \text { days } \\
\text { Day 3: } 200 \mathrm{~mL} \text { with cortisone acetate }\end{array}$ & $\begin{array}{l}\text { Cortisone: } \uparrow 8.6 \%{ }^{\star} \\
\text { (NS) }\end{array}$ & \\
\hline & Healthy volunteers (20) & $\begin{array}{l}\text { Tolvaptan } 60 \mathrm{mg} \times 1 \\
\text { Single strength }(\mathrm{NSP}) \\
240 \mathrm{~mL} \times 1 \text { with tolvaptan }\end{array}$ & $\uparrow 73 \% \xi_{(\mathrm{NC})}$ & $\begin{array}{l}\text { Shoaf et al., } \\
2011\end{array}$ \\
\hline & Healthy volunteers (21) & $\begin{array}{l}\text { Colchicine } 0.6 \mathrm{mg} \times 1 \text { on Day } 4 \\
\text { "Undiluted" (NSP) } \\
\text { Pre-treatment: } 240 \mathrm{~mL} \text { bid } \times 3 \text { days Day } 4: 240 \mathrm{~mL} \\
\text { with colchicine, } 240 \mathrm{~mL} \times 1 \text { per pre-treatment } \\
\text { schedule }\end{array}$ & $\uparrow 2.7 \% \%^{\dagger}(\mathrm{NS})$ & $\begin{array}{l}\text { Wason et al., } \\
2011\end{array}$ \\
\hline & $\begin{array}{l}\text { Hyperlipidemic patients } \\
\text { (130; Arm A: 60, Arm B: }\end{array}$ & $\begin{array}{l}\text { Atorvastatin } 10 \text { to } 40 \mathrm{mg} \text { daily per patient's } \\
\text { prescribed regimen (Arm A) }\end{array}$ & $\begin{array}{l}\operatorname{Arm} \mathrm{A}: \uparrow 19 \%^{\wedge}(\mathrm{p}< \\
0.05)\end{array}$ & $\begin{array}{l}\text { Reddy et al., } \\
2011\end{array}$ \\
\hline & & $\begin{array}{l}\text { Atorvastatin } 5 \text { to } 20 \mathrm{mg} \text { daily per patient's } \\
\text { prescribed regimen (Arm B) } \\
\text { Normal strength (NSP, Florida) } \\
300 \mathrm{~mL} \text { with atorvastatin } \times 90 \text { days }\end{array}$ & $\begin{array}{l}\text { Arm B: } \downarrow 26 \%^{\wedge} \\
(\mathrm{p}<0.001)\end{array}$ & \\
\hline & $\begin{array}{l}\text { Chronic myelogenous } \\
\text { leukemia patients (4) }\end{array}$ & $\begin{array}{l}\text { Imatinib } 400 \mathrm{mg} \text { daily } \\
\text { Normal strength (Tropicana; Kirin, Tokyo, Japan) } \\
250 \mathrm{~mL} \text { with imatinib } \times 7 \text { days }\end{array}$ & $\uparrow 1.6 \% \pi(\mathrm{p}=0.715)$ & $\begin{array}{l}\text { Kimura et al., } \\
2011\end{array}$ \\
\hline Seville orange & Healthy volunteers (23) & $\begin{array}{l}\text { Colchicine } 0.6 \mathrm{mg} \times 1 \text { on Day } 4 \text { "Undiluted" }(\mathrm{NSP}) \\
\text { Pre-treatment: } 240 \mathrm{~mL} \text { bid } \times 3 \text { days } \\
\text { Day } 4: 240 \mathrm{~mL} \text { with colchicine, } 240 \mathrm{~mL} \times 1 \text { per } \\
\text { pre-treatment schedule }\end{array}$ & $\downarrow 21 \%$ (SS) & $\begin{array}{l}\text { Wason et al., } \\
2011\end{array}$ \\
\hline \multicolumn{5}{|c|}{ * published since August 2010} \\
\hline \multicolumn{5}{|c|}{$t^{\dagger}$ geometric mean AUC } \\
\hline \multicolumn{5}{|c|}{$\begin{array}{l}\# \text { Cortisone acetate administered orally is converted to cortisol by hepatic } 11 \beta \text {-hydroxysteroid dehydrogenase type } 1 \text {. Circulating cortisol and } \\
\text { cortisone are metabolized mainly by } 5 a / \beta \text {-reductases, but CYP3A } 4 \text { also may contribute. }\end{array}$} \\
\hline \multicolumn{5}{|l|}{ median AUC } \\
\hline \multicolumn{5}{|l|}{$\xi_{\mathrm{n}=15}$} \\
\hline \multicolumn{5}{|c|}{ 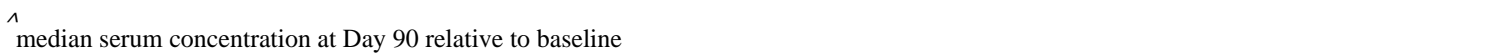 } \\
\hline
\end{tabular}

tid, three times a day; bid, two times a day; NS, not statistically significant; NSP, not specified; NC, not calculated; SS, statistically significant as reflected by $90 \%$ confidence interval outside $80-125 \%$ range (i.e., no interaction range) 
Table 2

Potential explanations for lack of concordance between in vitro and in vivo dietary substance-drug interaction studies

- Lack of authentication and/or misidentification of source material

- Inadequate description of raw materials

- Commercially available: brand name, manufacturer, lot number, ingredients, preparation directions, manufacturing process, origins of growth and production

- $\quad$ Freshly prepared: scientific name, quantity, plant part used, site of collection, preparation procedures, storage conditions

- $\quad$ Adulteration of product (e.g., contamination with other substances)

- Use of inconsistent product brand and lots

- Insufficient analysis (e.g., physicochemical properties, biochemical activity, in vivo PK) of active constituents and/or metabolites in each batch being studied by a validated analytical method

- $\quad$ Species differences in metabolism and transport pathways

- Pharmacogenetic variations

- Poorly designed in vitro experiments related to cell systems, assay conditions (e.g., enzyme/transport protein probe substrate(s), negative and positive controls, proper concentrations of inhibitors and/or inducers), analytical methods

- Suboptimal clinical trial design related to adequate number of subjects (to achieve statistical power), dietary restriction(s) prior to and/or during study participation, randomization, blinding, placebo, positive controls, selection of enzyme/transport protein probe substrate, inhibitor and/or inducer dose(s) and dosing schedule, sampling times

- Scarce information on PK-PD relationship of dietary substance or specific active ingredients

- Extrapolation of conclusions based on one preparation

Adapted from Farkas and Greenblatt, 2008 and Glisson and Walker, 2010 


\section{Table 3}

Questions to consider when reviewing clinical dietary substance-drug interaction studies

1 For a commercially available product, were the following provided - brand name, manufacturer, lot number, ingredients on label, preparation and storage directions, manufacturing process, origin(s) of growth and production?

2 Were any relevant/suspected bioactive constituent(s) measured by a validated analytical method?

3 Was the sample size justified by a power calculation?

4 If assay sensitivity was not an issue, were the sampling times appropriate (i.e., full PK profile captured)?

5 For single or multiple dosing of the drug or dietary substance, was the given dose a typically consumed/recommended/prescribed dose (i.e., reflective of 'real world' situations)?

6 Were dietary restrictions imposed on the subjects during the study period? Was a diet history taken prior to and/or during the study period?

7 Was pharmacogenetics considered as a source of variability? 
Table 4

General framework for quantitative prediction of dietary substance-drug interactions involving CYP inhibition as a major underlying mechanism

\section{PBPK Modeling Tools *}

1. Characterization of physicochemical properties ${ }^{\dagger}$ of drug and phytochemical inhibitor

2. Identification and quantification of clearance pathway(s) based on in vitro and/or in vivo studies

-liver/intestine/kidney/etc.: CYP, non-CYP, transport

3. Model-building based on information from Steps 1 and 2

4. Simulation of plasma concentration-time profile(s) of drug

5. Comparison of simulated plasma concentration-time profile(s) with observed in vivo PK data

6. Model refinement based on comparison of estimated parameters with those obtained from in vivo $\mathrm{PK}$

-Conduct sensitivity analysis if necessary

7. Simulation of plasma concentration-time profile(s) of phytochemical inhibitor

8. Comparison of simulated plasma concentration-time profile(s) with observed in vivo PK data ${ }^{t}$

9. Model refinement based on comparison of estimated parameters with those obtained from in vivo $\mathrm{PK}$

10. Simulation of plasma concentration-time profile(s) of drug with phytochemical inhibitor
acsIX, MATLAB-simulink, ADAPT, BerkeleyMadonna, MCSIM, SAAM II, GastroPlus, PKSim, Simcyp

$\mathrm{pK}_{\mathrm{a}}, \log \mathrm{P}, \mathrm{f}_{\mathrm{u}}$ plasma, $\mathrm{B} / \mathrm{P}$ ratio, $\mathrm{P}_{\text {eff }}^{\#}$, solubility

$\mathrm{K}_{\mathrm{m}}, \mathrm{V}_{\max }, \mathrm{Cl}_{\mathrm{int}}, \mathrm{K}_{\mathrm{i}}$

$\mathrm{f}_{\mathrm{m}}$

$\mathrm{k}_{\text {inact }}, \mathrm{k}_{\mathrm{deg}}, \mathrm{k}_{\text {syn }}$

Physiological parameters: organ blood flows, tissue partition coefficients $\left(\mathrm{K}_{\mathrm{p}}\right)^{\dagger}$

Scaling factors (microsomes, primary cells $\rightarrow$ organ)

$\mathrm{C}_{\max }, \mathrm{AUC}, \mathrm{Cl}, \mathrm{Cl} / \mathrm{F}$

Visual predictive checks Prediction fold-error

$\mathrm{C}_{\max }, \mathrm{AUC}, \mathrm{Cl}, \mathrm{Cl} / \mathrm{F}$

Visual predictive checks Prediction fold-error

Drug: $\mathrm{AUC}_{\mathrm{i}} / \mathrm{AUC}$

Not all-inclusive list

${ }^{\#}$ BCS/BCDDS classification

'Measured experimentally or predicted using software

${ }^{t}$ Not always measurable

$\mathrm{B} / \mathrm{P}$, blood to plasma ratio; $\mathrm{Cl}_{\text {int }}$, intrinsic clearance; $\mathrm{f}_{\mathrm{m}}$, fraction metabolized; $\mathrm{f}_{\mathrm{u}}$, fraction unbound in plasma; $\mathrm{P}_{\mathrm{eff}}$, effective intestinal permeability; $\mathrm{k}_{\mathrm{deg}}$, rate of degradation, $\mathrm{k}_{\mathrm{inact}}$, rate of inactivation; $\mathrm{k}_{\mathrm{synth}}$, rate of synthesis; $\mathrm{Cl} / \mathrm{F}$, apparent oral clearance; $\mathrm{AUC}$ / $/ \mathrm{AUC}$, ratio of drug AUC in presence of inhibitor to AUC without inhibitor 